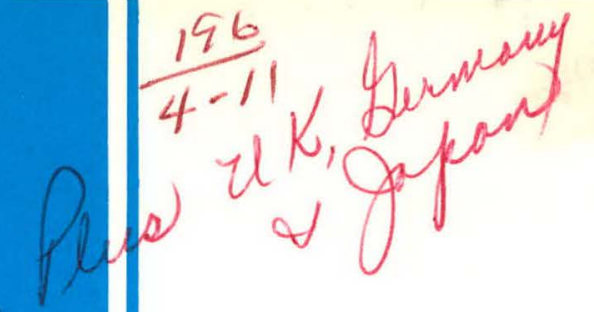

\title{
THE ORNL BENCHMARK EXPERIMENT FOR NEUTRON TRANSPORT IN IRON AND STAINLESS STEEL
}

\author{
R. E. Maerker \\ F. J. Muckenthaler
}

\section{OAK RIDGE NATIONAL LABORATORY}




\section{DISCLAIMER}

This report was prepared as an account of work sponsored by an agency of the United States Government. Neither the United States Government nor any agency Thereof, nor any of their employees, makes any warranty, express or implied, or assumes any legal liability or responsibility for the accuracy, completeness, or usefulness of any information, apparatus, product, or process disclosed, or represents that its use would not infringe privately owned rights. Reference herein to any specific commercial product, process, or service by trade name, trademark, manufacturer, or otherwise does not necessarily constitute or imply its endorsement, recommendation, or favoring by the United States Government or any agency thereof. The views and opinions of authors expressed herein do not necessarily state or reflect those of the United States Government or any agency thereof. 


\section{DISCLAIMER}

Portions of this document may be illegible in electronic image products. Images are produced from the best available original document. 


\begin{tabular}{|c|}
\hline Printed in the United States of America. Available from \\
National Technical Information Service \\
U.S. Department of Commerce \\
5285 Port Royal Road, Springfield, Virginia 22151 \\
Price: Printed Copy $\$ 3.00 ;$ Microfiche $\$ 0.95$ \\
\hline
\end{tabular}

This report was prepared as an account of work sponsored by the United States Government. Neither the United States nor the United States Atomic Energy Commission, nor any of their employees, nor any of their contractors, subcontractors, or their employees, makes any warranty, express or implied, or assumes any legal liability or responsibility for the accuracy, completeness or usefulness of any information, apparatus, product or process disclosed, or represents that its use would not infringe privately owned rights. 
ORNL-TM-4I69

UC-79d Liquid Metal Fast

Breeder Reactors Physics

Contract No. W-7405-eng-26

Neutron Physics Division

THE ORNL BENCHMARK EXPERIMENT FOR NEUTRON TRANSPORT

IN IRON AND STAINLESS STEEL*

R. E. Maerker and F. J. Muckenthaler

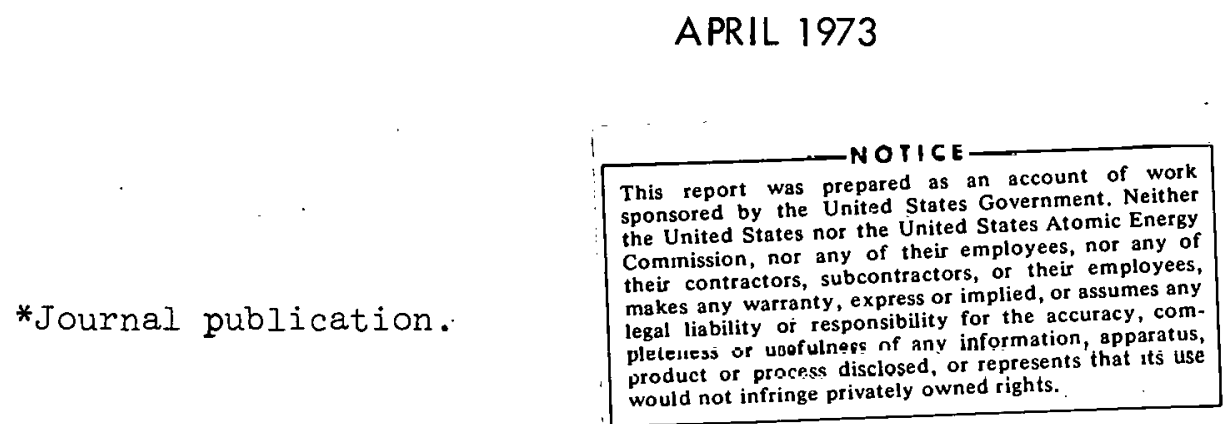

NOTICE This document contains information of a preliminary nature and was prepared primarily for internal use at the Oak Ridge National Laboratory. It is subject to revision or correction and therefore does not represent a final report.

OAK RIDGE NATIONAL LABORATORY

Oak Ridge, Tennessee 37830 operated by

Union Carbide Corporation for the

U.S. ATOMIC ENERGY COMMISSION 


\section{TABLE OF CONTENTS}

Page No.

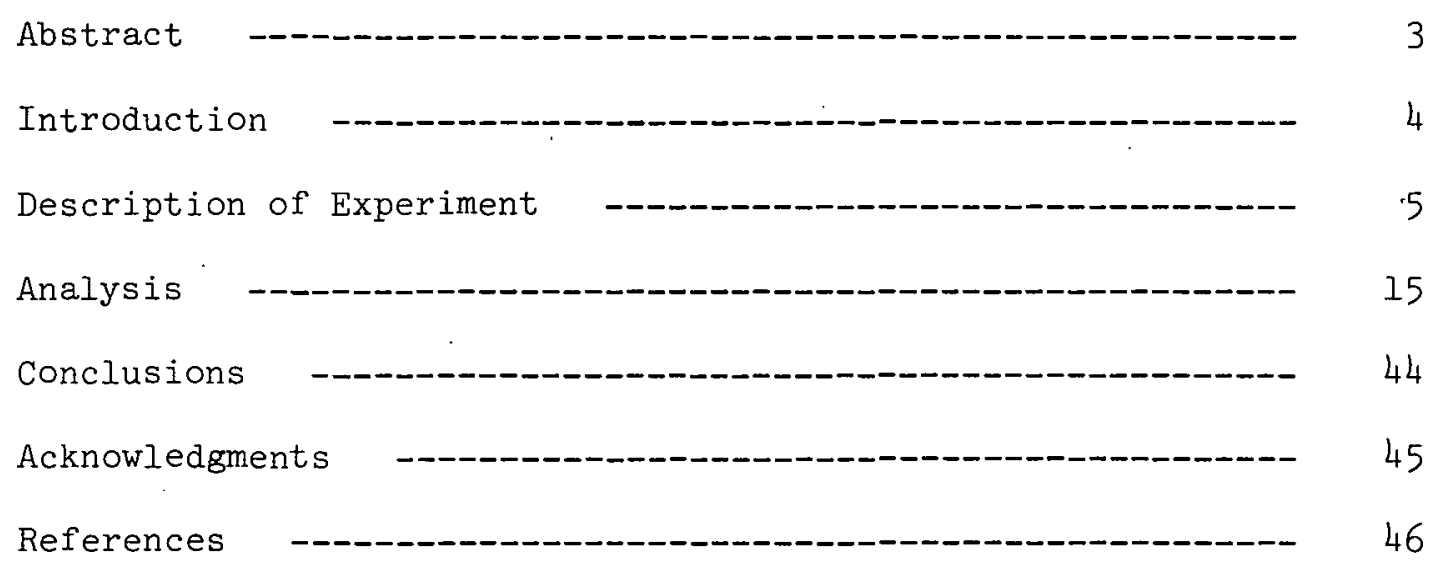

4 45 


\begin{abstract}
A description is presented of an experiment performed at the Tower Shielding Facility which provides verification of the accuracy of the available neutron cross sections for use in transport calculations of deep penetration of neutrons through up to $3 \mathrm{ft}$ of iron and $18 \mathrm{in}$. of stainless steel. Calculations of the experiment were performed with a special version of the MORSE multigroup Monte Carlo code. which uses point total cross sections. Comparison of the calculations using the new MAT 4180-mod 1 iron cross-section set with experiment indicates that the absolute neutron leakage spectra above thermal energies arising from scattering that penetrate up to $1 \mathrm{ft}$ of iron or $18 \mathrm{in.}$ of stainless steel can be calculated to within about $20 \%$, and the total neutron leakage above thermal energies penetrating up to $3 \mathrm{ft}$ of iron can also be calculated to about the same accuracy.
\end{abstract}




\section{INTRODUCTION}

Both the top shield and the structural components in the design of the FTR contain a large amount of iron in the form of carbon and stainless steels, and the iron therefore constitutes an important part of the neutron shield. The carbon steels consist of relatively pure iron, while the stainless steels contain considerable amounts of chromium and nickel. Since these steel components have thicknesses of the order of $3 \mathrm{ft}$, it is essential that accurate experimental results be available to verify transport calculations for deep penetration of neutrons through iron. Results from earlier experiments, 1 which were conducted for this purpose, have been somewhat limited in usefulness because of the relatively small iron thicknesses. Thus, for the present experiment, an iron shield 5 ft square and up to $3 \mathrm{ft}$ thick, and a stainless steel shield $5 \mathrm{ft}$ square and up to $18 \mathrm{in}$. thick were constructed for the experiment at the Tower Shielding Facility (TSF). Detailed measurements of the transmitted neutron spectra were made behind $1 \mathrm{ft}^{\prime}$ of iron and $18 \mathrm{in}$. of stainless steel, covering the energy range from $\sim 80 \mathrm{keV}$ to $10 \mathrm{MeV}$. Integral flux measurements were made with Bonner ball detectors behind thicknesses of iron varying from 1.5 in. to $3 \mathrm{ft}$ and from 1 to $1.5 \mathrm{ft}$ of stainless steel. The experimental results were compared with calculations performed using a special version of the MORSE multigroup Monte Carlo code employing point total cross sections. The comparisons of the calculated results with experimental results for the several spectrometers and also the integral detectors having widely varying energy responses have been utilized to determine the accuracy of the transport calculations using the latest available cross-section sets. 
Through sensitivity analysis, these results can be used to predict the dose uncertainty in a calculation for an LMFBR shield.

\section{DESCRIPTION OF THE EXPERIMENT}

A series of deep-penetration neutron transmission measurements through thick iron and stainless steel slabs have been performed at the TSF using a collimated beam of reactor neutrons as a source. These measurements were made behind various combinations of 5 -ft-square slabs; therefore, because the beam was tightly collimated, the effects of side leakage even for the 3-ft-thick sample of iron were negligible. Figure 1 shows a schematic of the experimental geometry for the thickest sample.

The thickness, density, and composition of the individual slabs used in the experiment were accurately determined. The density of the type 304 stainless steel slabs averaged $7.86 \mathrm{grams} / \mathrm{cm}^{3}$ and that of the iron slabs averaged 7.79 grams $/ \mathrm{cm}^{3}$. The average composition of the slabs is shown in Table I, where it is to be observed that the "iron" slabs were actually carbon steel.

Neutron spectral measurements beyond the iron or stainless steel sample were taken using three types of spectrometers. These were: (I) an NE-213 scintillator, which determines spectra in the energy range 0.8 to $15 \mathrm{MeV}$ with the aid of the unfolding code FERDOR; ${ }^{2}, 3$ (II) a Benjamin proton recoil spectrometer which determines spectra in the range $\sim 50 \mathrm{keV}$ to $1.5 \mathrm{MeV}$ with the aid of the unfolding code SPEC4; and (III) a $10^{4} \mathrm{~B}$ spectrometer ${ }^{5}$ which determines the spectra in the range thermal to $\sim 10 \mathrm{keV}$ with the aid of an iterative folding procedure. A set of three spherical 


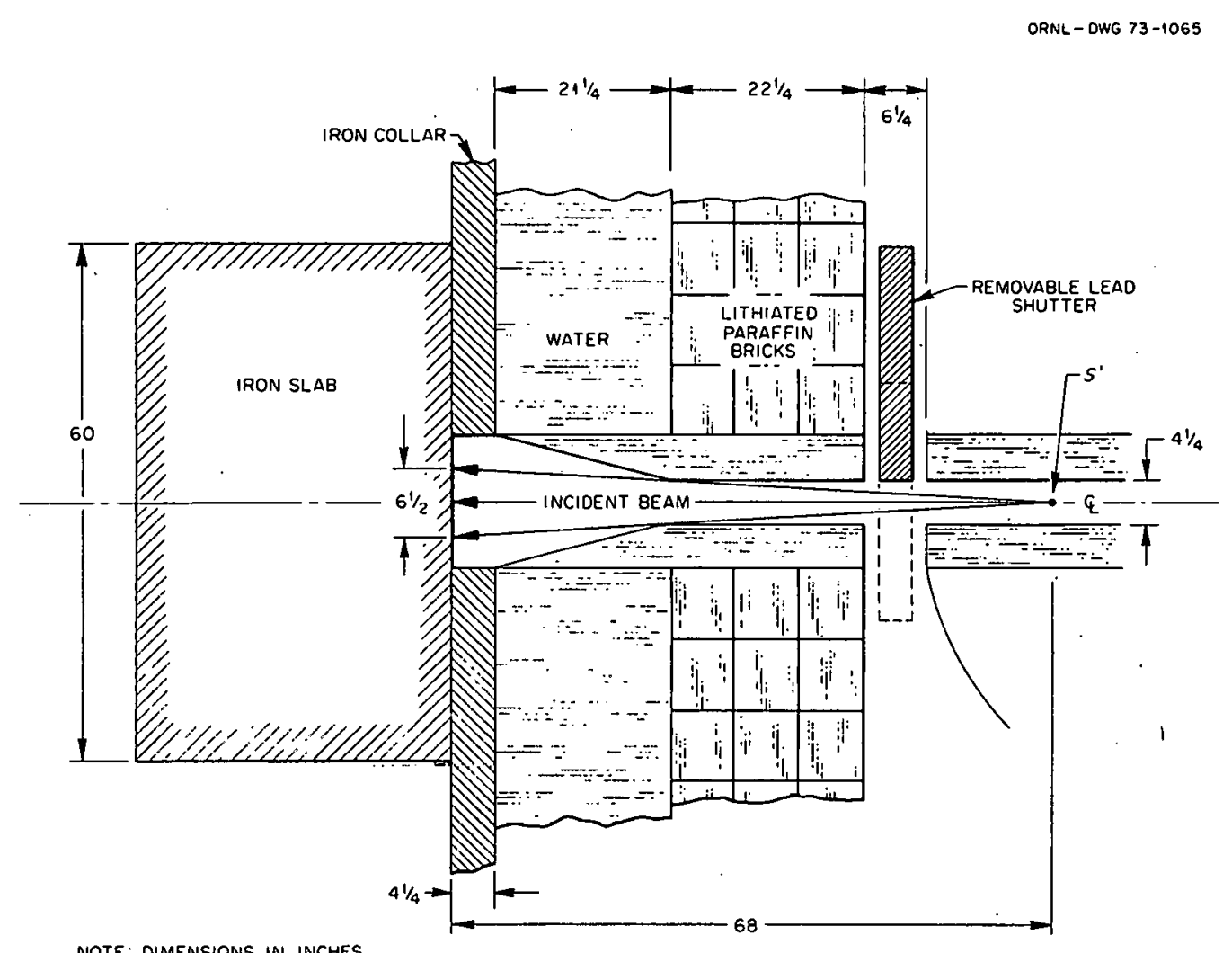

Fig. 1. Experimental Configuration for the 4-1/4-in.-diam Collimator with the 3-ft-Thick Iron Slab in Place. This collimator was used for all the measurements except those made behind $18 \mathrm{in}$. of stainless steel. 


\section{7}

Table I. Composition of the Slabs in Atoms/barn-cm

\begin{tabular}{lcc} 
& Iron Slabs & Stainless Steel Slabs \\
\hline Carbon & $9.815 \times 10^{-4}$ & - \\
Manganese & $5.150 \times 10^{-4}$ & $1.14 \times 10^{-3}$ \\
Iron & $8.372 \times 10^{-2}$ & $5.995 \times 10^{-2}$ \\
Chromium & - & $1.686 \times 10^{-2}$ \\
Nickel & - & $7.90 \times 10^{-3}$ \\
\hline
\end{tabular}


$\mathrm{BF}_{3}$ detectors surrounded by various thicknesses of polyethylene ( $1 / 2$ to 4 in.) and an outside shell of cadmium were also used to obtain integral flux measurements. "These "Bonner ball" detectors have response functions which peak in different regions of the neutron spectrum. A description of each Bonner ball is given in Table II. The response function of each Bonner ball was determined 6,7 as a function of energy to within a few percent utilizing ANISN adjoint calculations and calibrations with known sources. It is expressed in units of counts/second per unit neutron flux of energy E uniformly incident over the outside hemispherical surface of the ball.

Because of the importance of determining the characteristics of the neutron source for this experiment, measurements of the incident neutron beam were made with each of the three spectrometers. This provided a measured absolute energy spectrum from thermal to $10 \mathrm{MeV}$. The angular distribution of the source was also measured using several detectors by mapping of the beam in both the transverse and axial directions. These measurements established the fact that the tightly collimated source could be represented as a virtual point anisotropic source located 68 in. inside the collimator from the edge of the iron collar (point S' in Fig. I) with the beam intensity uniform over a diameter of $\sim 6-1 / 2$ in. at the mouth of the collimator and zero elsewhere.

The absolute source spectrum determined from the spectrometer measurements, and verified by the integral measurements, for the centerline point located on the exit plane of the collimator is shown in Fig. 2 for the region $100 \mathrm{eV} \leq \mathrm{E} \leq 10 \mathrm{MeV}$. The region below $100 \mathrm{eV}$ consists of a Maxwellian distribution and a l/E tail, and is unimportant for the 
Table II. Bonner Ball Description

Spherical, 2-in.-diam. ${ }^{10} \mathrm{BF}_{3}$ Proportional Counter Surrounded by Polyethylene and 0.030-in. Cd

\begin{tabular}{cccc}
$\begin{array}{c}\text { Standard } \\
\text { Bonner Bal1 } \\
\text { Designation }\end{array}$ & $\begin{array}{c}\text { Polyethylene } \\
\text { Thickness } \\
\text { (in.) }\end{array}$ & $\begin{array}{c}\text { Polyethylene } \\
\text { Density } \\
\left.\text { (grams } / \mathrm{cm}^{3}\right)\end{array}$ & $\begin{array}{c}\text { Diameter } \\
\text { of Ba11 } \\
\text { (in.) }\end{array}$ \\
\hline 3 & 0.515 & 0.951 & 3.09 \\
6 & 1.91 & 0.925 & 5.88 \\
10 & 3.90 & 0.951 & 9.86 \\
\hline
\end{tabular}




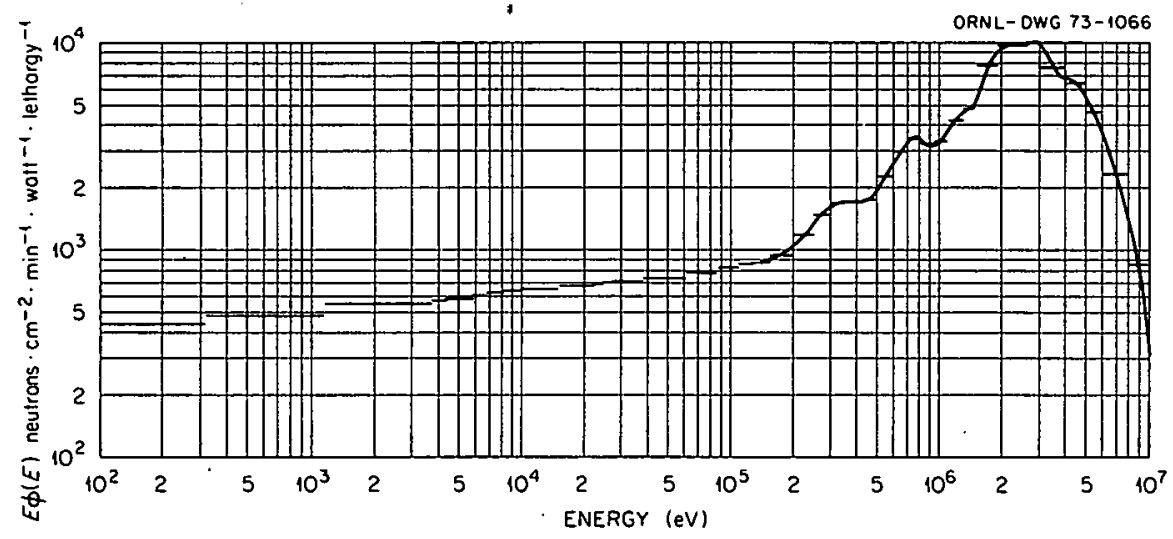

Fig. 2. Neutron Beam Source Spectrum on the Centerline at the Outside Edge of the 4-1/4-in.-diam Collimator. 
calculations reported here. The accuracy of the absolute magnitude of the incident spectrum is estimated to be $\pm 10 \%$ down to $200 \mathrm{keV}$ and $\pm 20 \%$ below $200 \mathrm{keV}$. The energy resolution varies ifrom $30 \%$ at I $\mathrm{MeV}$ to about $10 \%$ at $10 \mathrm{MeV}$. Below $\mathrm{I} \mathrm{MeV}$, the resolution is constant at about 10\%, down to 100 $\mathrm{keV}$. The ratio of surface-integrated current over the collimator to centerline current is $212.5 \mathrm{~cm}^{2}$.

All of the measurements made behind the iron and stainless steel slabs are summarized in Tables III and IV, respectively. Note that all of the measurements behind $18 \mathrm{in}$. of stainless steel were made using the reactor collimator shown in Fig. 3. For this collimator, the absolute source spectrum is very closely 7.4 times the spectrum shown in Fig. 2 for point A in Fig. 3, with the virtual source located 59.5 in. inside the collimator. The ratio of surface-integrated current over the collimator to centerline current is $1200 \mathrm{~cm}^{2}$ (ref. 8). The 3-in. and 6-in. Bonner balls used behind the 18 in. of stainless steel were also slightly different from those described in Table II. The 3-in. ball had a polyethylene thickness of $0.47 \mathrm{in.}$ and the 6-in. ball a polyethylene thickness of $1.97 \mathrm{in.}$, both of density 0.951 grams $/ \mathrm{cm}^{3}$.

The effects of any transverse leakage combined with subsequent air and ground scattering were quantitatively measured for each foreground measurement by placing a thick hydrogenous shield about halfway between the detector and the back face of the slabs in such a way that leakage from the back face of the slabs was eliminated. 'l'hese background measurements (generally, a few percent of the corresponding foreground measurements) were subtracted from all the foreground measurements (i.e., measurements obtaincd in the abscnee of the hydrogenous shaduw shield). 
Table III. Experimental Configurations for the Iron Transmission Measurements

\begin{tabular}{|c|c|c|c|c|}
\hline \multirow{4}{*}{$\begin{array}{l}\text { Iron Slab } \\
\text { Thickness } \\
\text { (in.) }\end{array}$} & \multicolumn{3}{|c|}{ Detector Locations } & \multirow[b]{4}{*}{ Detector Type } \\
\hline & \multirow{2}{*}{$\begin{array}{l}\text { Centerline } \\
\text { Distance }\end{array}$} & \multirow{2}{*}{$\begin{array}{c}\text { Radial } \\
\text { Distance }\end{array}$} & \multirow{2}{*}{ Observation Angle ${ }^{a}$} & \\
\hline & & & & \\
\hline & $\begin{array}{l}\text { Behind Slab } \\
\text { (in.) }\end{array}$ & $\begin{array}{l}\text { From Centerline } \\
\text { (in.) }\end{array}$ & $\begin{array}{c}\text { With Respect to } € \\
\text { (deg) }\end{array}$ & \\
\hline \multirow[t]{3}{*}{0.52} & 127 & 0 & 0 & ${ }^{10} \mathrm{~B}$ Spectrometer \\
\hline & 123 & 33 & 15 & 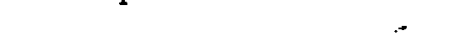 \\
\hline & 90 & 90 & 45 & . \\
\hline \multirow[t]{6}{*}{1.55} & 152 & 0 & 0 & Bonner Balls \\
\hline & 146 & 39 & 15 & \\
\hline & 107 & 107 & 45 & \\
\hline & 126 & 0 & 0 & TOB Spectrometer \\
\hline & 122 & 32.5 & 15 & \\
\hline & 89 & 89 & 45 & \\
\hline \multirow[t]{2}{*}{4.05} & 158 & 42.5 & 15 & NE-213 Spectrometer \\
\hline & 116 & 116 & 45 & $\therefore$ \\
\hline 6.06 & 162 & 0 & 0 & NE-213 Spectrometer \\
\hline \multirow[t]{6}{*}{12.13} & 141 & 0 & 0 & Bonner Balls \\
\hline & 136 & 36.5 & 15 & \\
\hline & 100 & 100 & 45 & \\
\hline & 156 & 0 & 0 & NE-213 Spectrometer \\
\hline & 150 & 40.5 & 15 & \\
\hline & 110 & 110 & 45 & \\
\hline \multirow[t]{2}{*}{12.25} & 10 & 0 & 0 & Benjamin Spectrometer \\
\hline & 10 & 12 & 50 & \\
\hline \multirow[t]{3}{*}{24.41} & 128 & 0 & 0 & Bonner Balls \\
\hline & 124 & 33 & 15 & \\
\hline & 90.5 & 90.5 & 45 & \\
\hline \multirow[t]{3}{*}{36.56} & 115 & 0 & . 0 & Bonner Balls \\
\hline & 111 & 30 & 15 & \\
\hline & 81.5 & 81.5 & 45 & \\
\hline
\end{tabular}

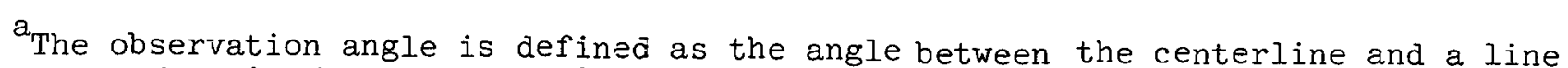
connecting the detector and the nidpoint of the emergent face of the slab. The vertex of this angle is the pivot point for the angular traverses. 
Table IV. Experimental Configurations for the Stainless

Steel Transmission Measurements

\begin{tabular}{|c|c|c|c|c|}
\hline \multirow[b]{2}{*}{$\begin{array}{c}\text { Stainless Steel Slab } \\
\text { Thickness } \\
\text { (in.) }\end{array}$} & \multicolumn{3}{|c|}{ Detector Locations } & \multirow[b]{2}{*}{ Detector Type } \\
\hline & $\begin{array}{l}\text { Centerline } \\
\text { Distance } \\
\text { Behind Slab } \\
\quad \text { (in.) }\end{array}$ & $\begin{array}{c}\text { Radial } \\
\text { Distance } \\
\text { From Centerline } \\
\text { (in. }\end{array}$ & $\begin{array}{l}\text { Observation Angle } \\
\text { With Respect to } E \\
\text { (deg) }\end{array}$ & \\
\hline 12.17 & $\begin{array}{r}141 \\
136 \\
100 \\
\end{array}$ & $\begin{array}{r}0 \\
36.5 \\
100 \\
\end{array}$ & $\begin{array}{r}0 \\
15 \\
45 \\
\end{array}$ & Bonner Balls \\
\hline & $\begin{array}{l}10 \\
10\end{array}$ & $\begin{array}{r}0 \\
12\end{array}$ & $\begin{array}{r}0 \\
50\end{array}$ & Benjamin Spectrometer \\
\hline $18.33^{b}$ & $\frac{\frac{12+144}{47.7}}{12}$ & $\frac{0}{0}$ & $\frac{0}{0}$ & $\frac{\text { Bonner Balls }}{\text { NE-213 Spectrometer }}$ \\
\hline
\end{tabular}

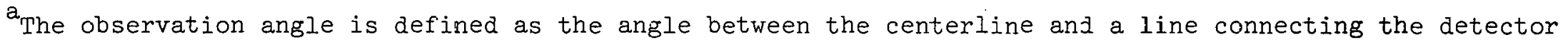
with the ridpoint of the emergent face of the slab. The vertex of this angle is the pivot point for the angular traverses.

${ }^{\mathrm{b}} \mathrm{All}$ measurements behind 18 in. of stainless steel were made using the collimator described in Fig. 3. The 3-in. and 6-in. Bonner ba-ls were also of slightly different dimensions than those described in. Table II. See text. 
ORNL-DWG 72-7405R2

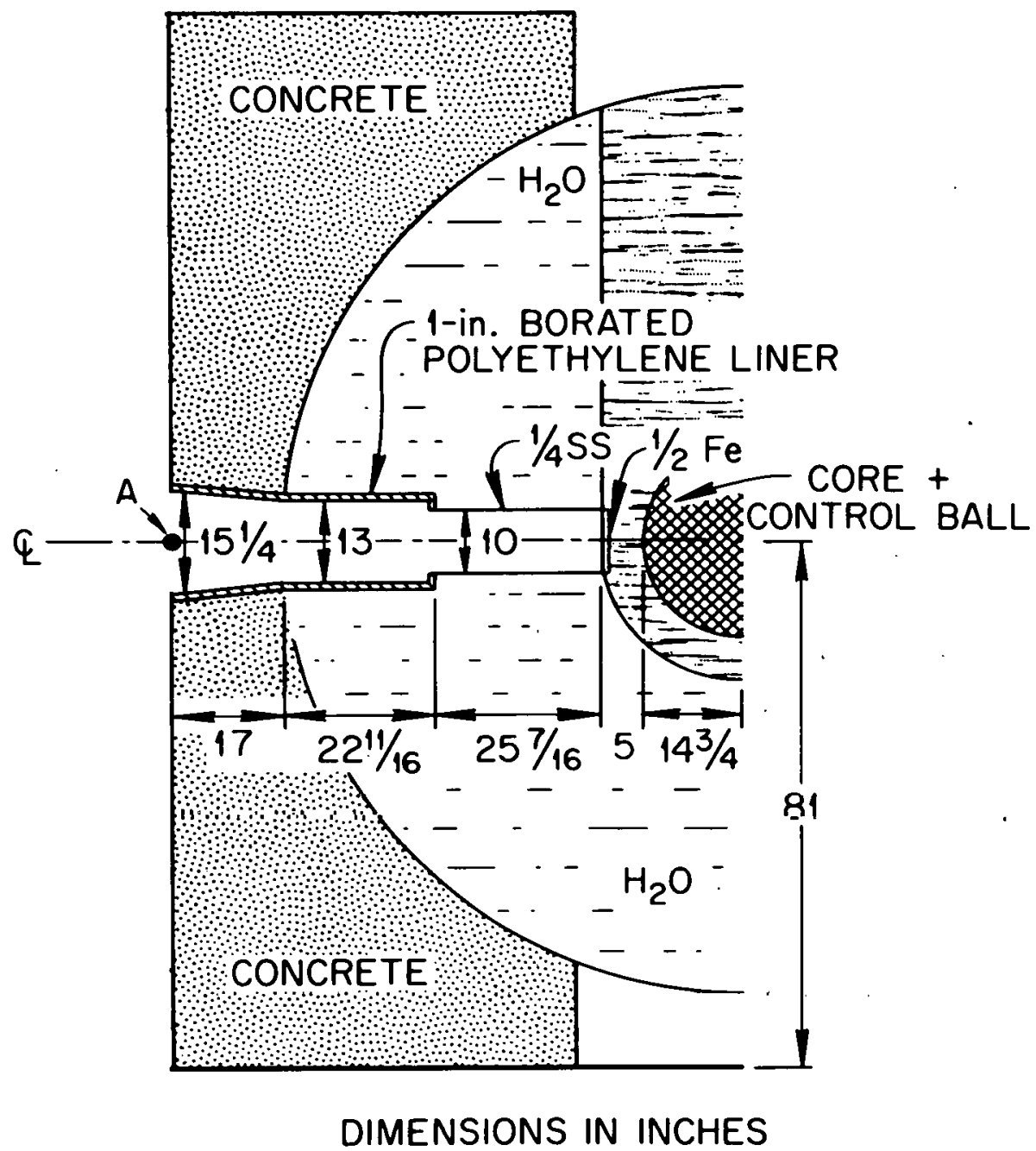

Fig. 3. Experimental Configuration for the 15-1/4-in.-diam Collimator Used for the Measurements Made Behind 18 in. of Stainless Steel Only. 
ANALYSIS

In the analysis of the experiment Monte Carlo calculations of the transport of neutrons above thermal energies were performed using the multigroup code MORSE. ${ }^{9}$ The basic cross-section data set used for iron was an updated version of the present ENDF/B-III set (MAT 1180) designated 4180-Mod 1 (ref. 10). This updated set differs from the version III set in that it incorporates the recent measurements of Harvey ${ }^{11}$ of crosssection minima in the region 80 to $500 \mathrm{keV}$, includes better differential elastic scattering cross-section data in the region 0.4 to $1.4 \mathrm{MeV}$, contains modifications in the excitation function of the first excited level for inelastic scattering, and provides an extension of cross-section data up to $20 \mathrm{MeV}$. The basic cross-section data set used for chromium, nickel, manganese, and carbon were the ENDF/B-III sets with MAT numbers designated as 1121, 1123, 1019, and 1165, respectively. The point data for carbon steel were processed with SUPERTOG ${ }^{12}$ into a set of multigroup cross sections weighted $1 / E \Sigma_{T}$ having a 220 -group structure designed to conform to the iron total cross-section structure with a $P_{3}$ approximation for the elastic scattering angular distributions. In addition, total macroscopic cross-section data at over 6000 energy points in the region $15 \mathrm{keV}$ to $10 \mathrm{MeV}$ were incorporated into MORSE. The "point" data were used to calculate the uncollided flux analytically as well as to sample more accurately the location of the next collision point in the random walk procedure and the next flight estimator in the statistical estimation technique. 
For stainless steel, a 218-group structure very similar to the carbon steel group structure was used. In addition, the iron data set used in the stainless steel analysis was a preliminary version of 4180-Mod. 1 . It was very similar, although not identical, to the final version used in the carbon steel analysis, however, and incorporated preliminary results of the measurements of Harvey of the minima in the region 80 to $500 \mathrm{keV}$. Aside from different compositions, the multigroup sets thus differed slightly for carbon steel and stainless steel both in group structure and in the basic iron data set used. The total macroscopic cross-section data at over 6000 energy points for the stainless steel were also based on the preliminary 4180-Mod. I data set for iron for all the calculations behind the 12 in. of stainless steel. For the calculations behind 18 in. of stainless steel, the total cross sections incorporated the 4180-Mod. I iron set.

Since the experiment can be adequately represented geometrically as two dimensional, the calculations employed cylindrical geometry in describing the reactor collimator and the iron collar and water shield surrounding it. Effects due to multiple reflection between the slab samples and the reactor collimator, including both the iron collar and water shield surrounding the collimator, were explicitly and separately calculated and were added to the results obtained with a vacuum boundary at the front and back of the slabs. The calculations employed little biasing since the most important effect of the many windows in iron, which control the transmission, is easily calculated provided the cross-section structure is represented in adequate detail. 
Comparisons of the measured Bonner ball counting rates on the centerline with counting rates obtained by folding the calculated spectral fluxes incident on the balls with the Bonner ball response functions are shown in Figs. 4-6. The response functions for each of the three Bonner balls are also presented in these figures. The corresponding off centerline comparisons are shown in Table $\mathrm{V}$, and the comparisons behind 18 in. of stainless steel using a different collimator are summarized in Table VI. It should be emphasized that in these and all succeeding calculations, the effects of air attenuation both in the derivation of the source appearing in Fig. 2 and in the slab transmitted fluxes to the detectors are ignored, and can result in overestimates of the calculated fluxes at the detector by amounts varying between 0 and $10 \%$.

An inspection of these comparisons shows that in general the agreement is satisfactory and hence for calculation of these configurations apparently no serious deficiencies exist in the new cross-section set used for iron. Earlier calculations of this experiment using less accurate iron cross sections, i.e., the Irving-Straker set (MAT 1101) and an early version of the ENDF/B-III set (MAT 1124), generally resulted in predicting lower counting rates than those from the present calculations, and, in particular, the Irving-Straker set underpredicted many of the Bonner ball measurements by factors of two to three primarily because of significant errors in the $24 \mathrm{keV}$ window. 13 Since the estimated errors in the calculated counting rates involve uncertainties of the order of $\pm 5 \%$ due to statistics and uncertainties of about $\pm 10 \%$ in the assumed absolute source spectrum, and given the estimated reproducibility of the measurements as $\pm 5 \%$, agreement between calculated and measured results can be expected to lie only 


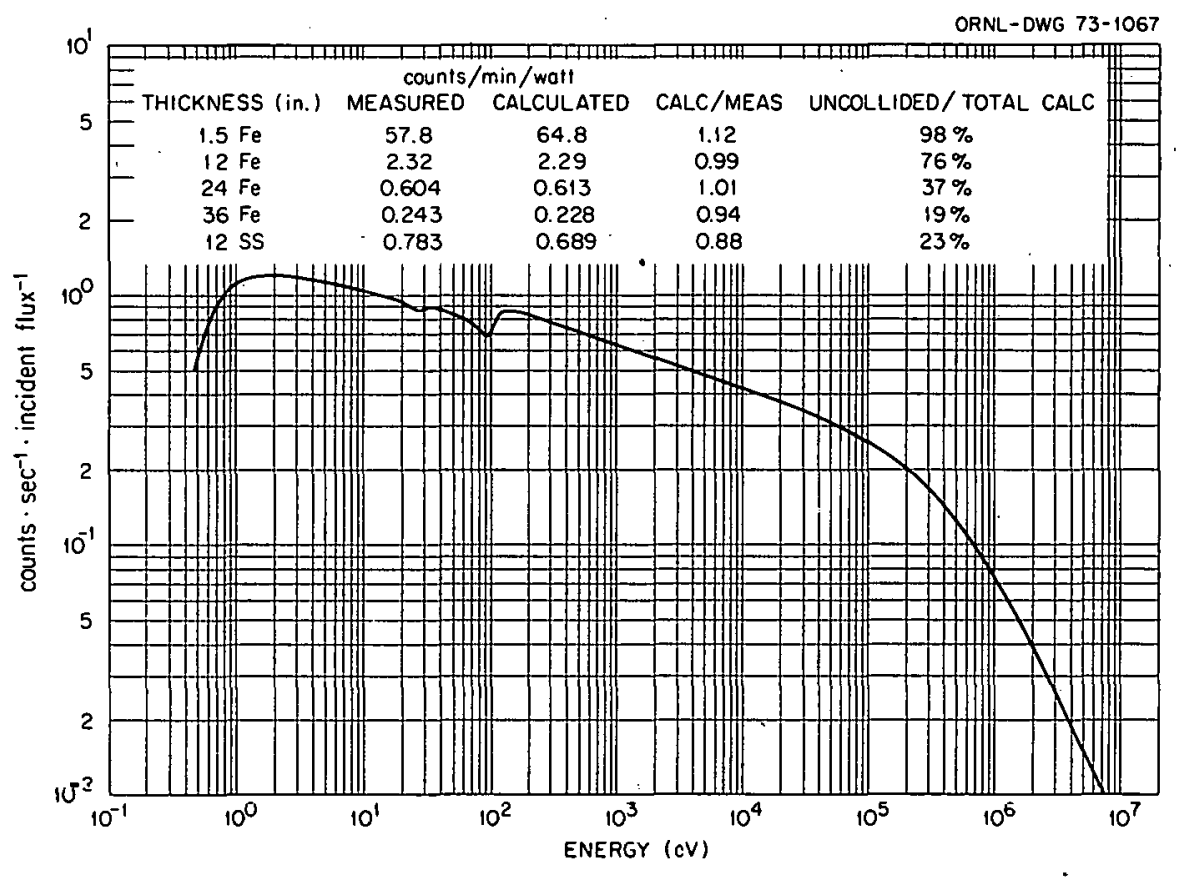

Fig. 4. Three-Inch Bonner Ball Results on the Centerline. Comparison of calculated and measured counting rates and its response function. 


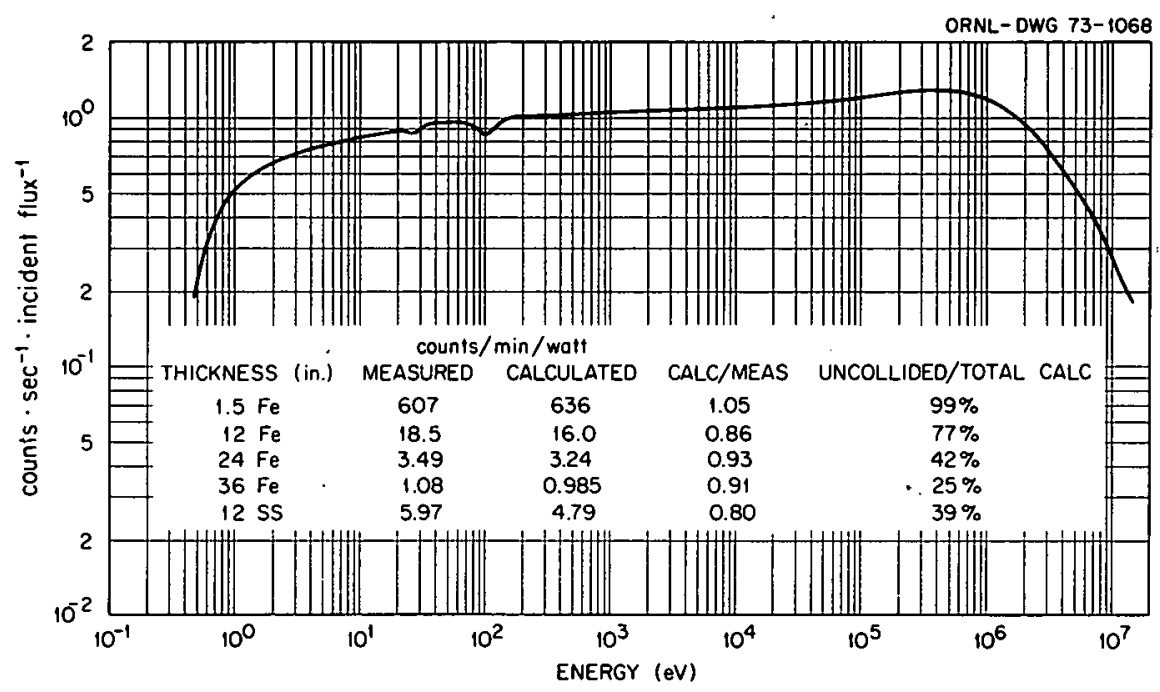

Fig. 5. Six-Inch Bonner Ball Results on the Centerline. Comparison of calculated and measured counting rates and its response function. 


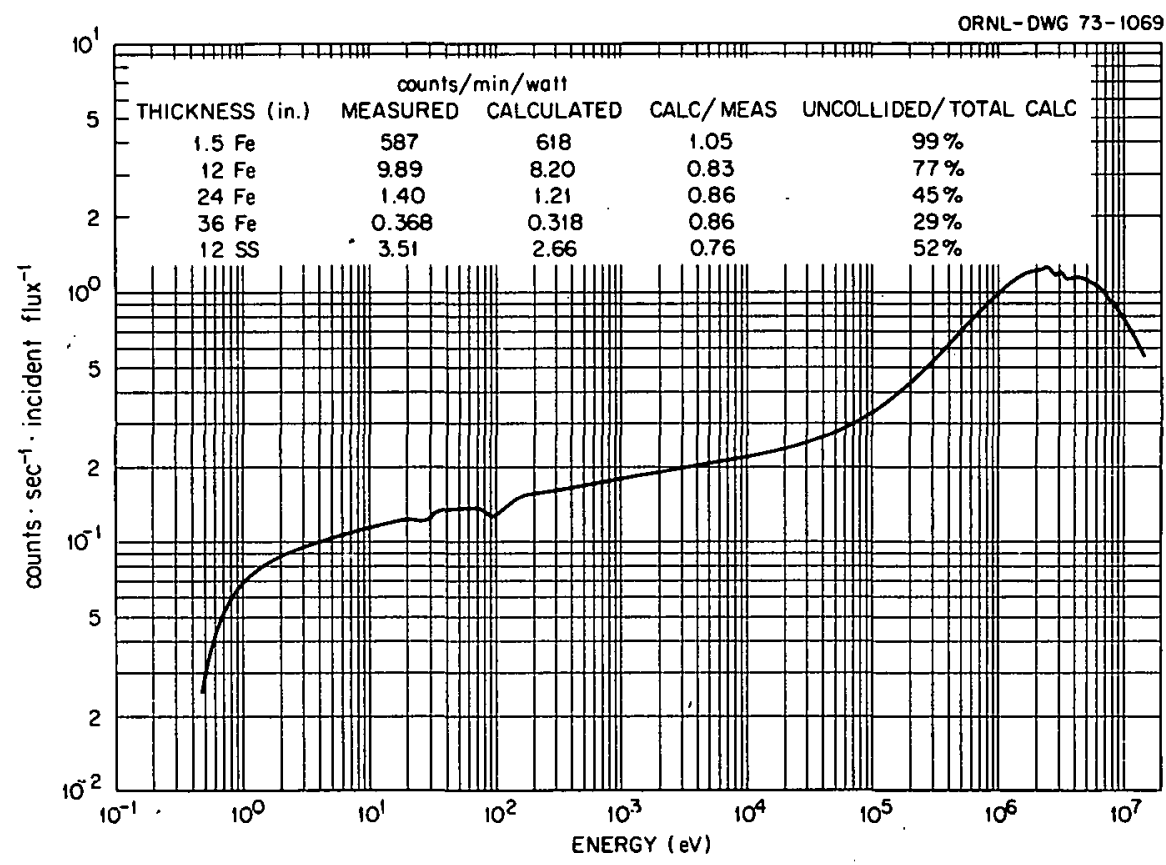

Fig. 6. Ten-Inch Bonner Ball Results on the Centerline. Comparison of calculated and measured counting rates and its response function. 
Table V. Comparison of Calculated and Measured Bonner Ball 'Counting Rates off the Centerline in.Counts/min/watt

\begin{tabular}{|c|c|c|c|c|c|c|}
\hline & \multicolumn{2}{|c|}{ 3-in. BB } & \multicolumn{2}{|c|}{ 6-in. BB } & \multicolumn{2}{|c|}{ 10-in. BB } \\
\hline & $15^{\circ}$ & $45^{\circ}$ & $15^{\circ}$ & $45^{\circ}$ & $15^{\circ}$ & $45^{\circ}$ \\
\hline \multicolumn{7}{|c|}{1.5 in. $\mathrm{Fe}$} \\
\hline Measured & $1: 02$ & 0.680 & 5.22 & 2.82 & 4.74 & 1.99 \\
\hline Calculated & 1.02 & 0.680 & 4.61 & 2.86 & 4.18 & 2.19 \\
\hline Calc./meas. & 1.00 & 1.00 & 0.88 & 1.02 & 0.88 & 1.10 \\
\hline \multicolumn{7}{|c|}{12 in. $\mathrm{Fe}$} \\
\hline Measured & 0.577 & 0.411 & 3.54 & 2.39 & 1.58 & 1.04 \\
\hline Calculated & 0.538 & 0.372 & 3.49 & 2.37 & 1.64 & 1.09 \\
\hline Calc./meas. & 0.93 & 0.91 & 0.99 & 0.99 & 1.04 & 1.05 \\
\hline \multicolumn{7}{|c|}{24 in. $\mathrm{Fe}$} \\
\hline Measured & 0.367 & 0.245 & 1.70 & 1.13 & 0.600 & 0.405 \\
\hline Calculated & 0.380 & 0.267 & 1.85 & 1.28 & 0.630 & 0.427 \\
\hline Calc./meas. & 1.04 & 1.09 & 1.09 & 1.13 & 1.05 & 1.05 \\
\hline \multicolumn{7}{|c|}{36 in. $\mathrm{Fe}$} \\
\hline Measured & 0.181 & 0.128 & 0.700 & 0.475 & 0.227 & 0.151 \\
\hline Ca1culated & 0.179 & 0.123 & 0.709 & 0.493 & 0.216 & 0.150 \\
\hline Calc./meas. & 0.99 & 0.96 & 1.01 & 1.04 & 0.95 & 0.99 \\
\hline \multicolumn{7}{|c|}{12 in. SS } \\
\hline Measured & 0.496 & 0.327 & 2.74 & 1.77 & 1.28 & 0.797 \\
\hline Calculated & 0.508 & 0.324 & 2.79 & 1.76 & 1.21 & 0.743 \\
\hline Calc./meas. & 1.02 & 0.99 & 1.02 & 0.99 & 0.95 & 0.93 \\
\hline
\end{tabular}


Table VI. Comparison of Calculated and Measured Bonner Ball Counting Rates on the Centerline Behind 18 in. Stainless Steel in Counts/min/watt

\begin{tabular}{lccc}
\hline & 3-in. BB & 6-in. BB & 10-in. BB \\
\hline & 12 in. Behind Slab & \\
\hline Measured & 428 & 2500 & 1008 \\
Calculated & 463 & 2844 & 1074 \\
Calc./meas. & 1.08 & 1.14 & 1.07 \\
Calc. uncoll./total & $0.1 \%$ & $0.2 \%$ & $0.3 \%$ \\
\hline & 72 in. Behind S1ab & & \\
& 36.6 & 218 & 83.8 \\
Measured & 33.7 & 194 & 0.82 \\
Calculated & 0.92 & 0.89 & $1.8 \%$ \\
Calc./meas. & $0.3 \%$ & $1.0 \%$ & \\
Calc. uncoll./total & & & \\
\hline & 144 in. Behind S1ab & \\
\hline Measured & 9.67 & 59.8 & 0.80 \\
Calculated & 9.16 & 52.4 & $3.3 \%$ \\
Calc./meas. & 0.95 & 0.88 & \\
Calc. uncoll./total & $0.6 \%$ & $1.8 \%$ & \\
\hline
\end{tabular}


within about $\pm 10 \%$ even with no errors, in the cross sections. The only significant disagreement between the results of the present calculations with any of the Bonner ball measurement's, therefore, occurs on the centerline for the 6-in. and 10-in. Bonner balls behind the $12 \mathrm{in.} \mathrm{stainless}$ steel slab and for the 10-in. Bonner ball located at least 72 in. behind the 18-in. stainless steel slab, where the calculations average about 20\% low, and on the centerline for the 10-in. Bonner ball behind 12, 24 , and 36 in. of iron, where the calculations average about 15\% 10w. Since the 10-in. Bonner ball is more sensitive than the other Bonner balls to neutron energies above $0.5 \mathrm{MeV}$ relative to other energy regions (see Table VII), it seems probable that the cross-section set has some deficiencies in this energy range. For iron, the comparisons shown in Fig. 6 indicate that it may be the uncollided component that is in error, and hence that some total cross-section minima exist in iron in the region above $\sim 0.5$ MeV that are still not properly described in the evaluation. This will be pursued in somewhat greater detail following the presentation of the NE213 comparisons further on. For the stainless steel, the comparisons shown behind 12 in. also suggest a total cross-section error, since the disagreement occurs only on the centerline where there is an appreciable uncollided contribution. Further, there is some disagreement behind the 18-in. slab for the 10-in. Bonner ball at the larger distances where the uncollided contribution is still very small, which suggests the possibility of additional errors in the cross-section set, although these errors do not show up in the off centerline measurements behind the 12-in. slab.

Table VII shows the fraction of the calculated counting rates for each of the Bonner balls and of the total epicadmium flux incident on the 
Table VII. Percentage of Calculated Counting Rates and Epicadmium Fluxes Due to Neutrons in Various Energy Groups Incident on the Bonner Balls on the Centerline a

\begin{tabular}{|c|c|c|c|c|}
\hline Bonner Ball & $3-1 n . B B$ & 6-in. $B B$ & $10-1 n \cdot B B$ & Flux \\
\hline \multicolumn{5}{|c|}{ Iron thickness $=0$ in } \\
\hline $2.6-10 \mathrm{MeV}$ & 2.4 & 19.0 & 40.0 & 28.6 \\
\hline $1.0-2.6$ & 5.4 & 29.7 & 39.7 & 27.6 \\
\hline $0.7-1.0$ & 1.9 & 6.7 & 5.6 & 4.7 \\
\hline $0.43-0.7$ & 2.4 & 6.7 & 4.4 & 4.8 \\
\hline $0.25-0.43$ & 2.7 & 5.3 & 2.6 & 3.9 \\
\hline $0.11-0.25$ & 3.2 & 4.6 & 1.7 & 3.3 \\
\hline $30-110 \mathrm{keV}$ & 5.3 & 5.2 & 1.5 & 4.0 \\
\hline $10-30$ & 5.2 & 3.8 & 1.0 & 3.2 \\
\hline $1.14-10$ & 11.9 & 6.1 & 1.3 & 5.2 \\
\hline $0.41-1140 \mathrm{ev}$ & 59.6 & 12.9 & 2.2 & 14.7 \\
\hline \multicolumn{5}{|c|}{ Iron thickness $=12$ in } \\
\hline $2.6-10 \mathrm{MeV}$ & 0.1 & 0.6 & 2.0 & 1.0 \\
\hline $1.0-2.6$ & 3.7 & 10.5 & 22.7 & 12.7 \\
\hline $0.7-1.0$ & 5.1 & 10.7 & 15.4 & 10.5 \\
\hline $0.43-0.7$ & 13.0 & 20.1 & 22.2 & 19.0 \\
\hline $0.25-0.43$ & 21.5 & 25.6 & 21.1 & 23.7 \\
\hline $0.11-0.25$ & 17.3 & 14.5 & 9.1 & 13.9 \\
\hline $30-110 \mathrm{keV}$ & 6.0 & 3.4 & 1.6 & 3.5 \\
\hline $10-30$ & 31.7 & 14.3 & 5.8 & 15.3 \\
\hline $1.14-10$ & 0.6 & 0.2 & 0.1 & 0.2 \\
\hline $0.52-1140 \mathrm{ev}$ & 1.0 & 0.1 & 0.0 & 0.2 \\
\hline \multicolumn{5}{|c|}{ Iron thickness $=24 \mathrm{in}$} \\
\hline $2.6-10 \mathrm{MeV}$ & 0.0 & 0.0 & 0.0 & 0.0 \\
\hline $1.0-2.6$ & 0.2 & 0.7 & 2.1 & 0.9 \\
\hline $0.7-1.0$ & 1.4 & 3.9 & 7.7 & 3.9 \\
\hline $0.43-0.7$ & 6.7 & 13.7 & 21.0 & 13.1 \\
\hline $0.25-0.43$ & 17.8 & 27.5 & 31.5 & 26.0 \\
\hline $0.11-0.25$ & 21.2 & 23.2 & 19.4 & 22.5 \\
\hline $30-110 \mathrm{keV}$ & 9.5 & 7.1 & 4.7 & 7.4 \\
\hline $10-30$ & 39.1 & 21.8 & 13.1 & 24.8 \\
\hline $1.14-10$ & 1.8 & 0.7 & 0.3 & 0.8 \\
\hline $0.52-1140 \mathrm{ev}$ & 2.3 & 0.4 & 0.2 & 0.6 \\
\hline \multicolumn{5}{|c|}{ Iron thickness $=36 \mathrm{in}$} \\
\hline $2.6-10 \mathrm{MeV}$ & 0.0 & 0.0 & 0.0 & 0.0 \\
\hline $1.0-2.6$ & 0.0 & 0.1 & 0.2 & 0.1 \\
\hline $0.7-1.0$ & 0.4 & 1.2 & 2.7 & 1.2 \\
\hline $0.43-0.7$ & 2.9 & 7.3 & 12.5 & 6.9 \\
\hline $0.25-0.43$ & 12.3 & 23.2 & 31.3 & 21.5 \\
\hline $0.11-0.25$. & 20.5 & 28.2 & 27.3 & 26.7 \\
\hline $30-110 \mathrm{keV}$ & 10.2 & 9.4 & 7.1 & 9.6 \\
\hline $10-30$ & 35.6 & 25.2 & 16.1 & 27.1 \\
\hline $1.14-10$ & 4.5 & 2.2 & 1.2 & 2.4 \\
\hline $0.52-1140 \mathrm{ev}$ & 13.6 & 3.2 & 1.6 & 4.5 \\
\hline
\end{tabular}


Table VII (continued)

\begin{tabular}{|c|c|c|c|c|}
\hline Bonner Ball & 3-in. $B B$ & 6-in. $B B$ & 10-in. BB & Flux \\
\hline \multicolumn{5}{|c|}{ Stainless steel thickness $=12$ in. } \\
\hline $2.6-10 \mathrm{MeV}$ & 0.3 & $=1.4$ & $\cdot 4.2$ & 2.5 \\
\hline $1.0-2.6$ & 6.0 & 15.6 & 31.9 & 19.2 \\
\hline $0.7-1.0$ & 7.5 & 15.1 & 18.8 & 14.3 \\
\hline $0.43-0.7$ & 10.4 & 16.2 & 15.6 & 14.7 \\
\hline $0.25-0.43$ & 18.3 & 21.2 & 15.3 & 19.1 \\
\hline $0.11-0.25$ & 18.7 & 15.4 & 8.5 & 14.4 \\
\hline $30-110 \mathrm{keV}$ & 10.9 & 6.2 & 2.6 & 6.1 \\
\hline $10-30$ & 14.0 & 6.1 & 2.2 & 6.3 \\
\hline $1.14-10$ & 5.1 & 1.5 & 0.5 & 1.6 \\
\hline $0.52-1140 \mathrm{ev}$ & 8.8 & 1.3 & 0.4 & 1.8 \\
\hline \multicolumn{5}{|c|}{ Stainless steel thickness $=18$ in., detector 72 in. behind } \\
\hline $2.6-10 \mathrm{MeV}$ & 0.0 & 0.1 & 0.2 & 0.1 \\
\hline $1.0-2.6$ & 0.5 & 1.6 & 5.6 & 2.2 \\
\hline $0.7-1.0$ & 1.3 & 4.2 & 8.5 & 4.1 \\
\hline $0.43-0.7$ & 5.0 & 11.9 & 18.2 & 11.2 \\
\hline $0.25-0.43$ & 11.9 & 20.9 & 24.0 & 19.4 \\
\hline $0.11-0.25$ & 20.0 & 26.0 & 22.6 & 24.8 \\
\hline $30-110 \mathrm{keV}$ & 16.2 & 14.0 & 9.5 & 14.3 \\
\hline $10-30$ & 21.6 & 14.3 & 8.2 & 15.3 \\
\hline $1.14-10$ & 7.7 & 3.4 & 1.7 & 3.8 \\
\hline $0.52-1140 \mathrm{ev}$ & 15.8 & 3.6 & 1.5 & 4.8 \\
\hline
\end{tabular}

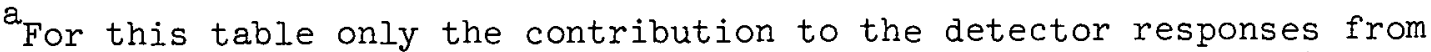
multiple reflection between the slabs (where they are present) and the collimator, including the iron collar, was neglected. For the centerline detector locations, this contribution was of the order of $10 \%$, and hence this omission does not materially alter the significance of the entries appearing in the table. 
Bonner balls due to neutrons in various energy regions for detector locations on the centerline. It is to be observed that the neutrons leaking the slabs are divided roughly equally among the energy regions presented between 10 and $700 \mathrm{keV}$, which reflects the equal importance of the windows above $24 \mathrm{keV}$ to that of the $24-\mathrm{keV}$ window itself.

In Figs. 7-9 comparisons are shown between the calculated and measured NE-2l3 spectra behind 6 in. and 4 in. of iron. All of the calculations of the NE-213 spectra were smoothed with the resolution function of the spectrometer. ${ }^{14}$ In general, undulations in the smoothed spectra above $3 \mathrm{MeV}$ are due to the coarse group structure used in the calculations, i:e., 3 to 4 $\mathrm{MeV}, 4$ to $5 \mathrm{MeV}, 5$ to $6 \mathrm{MeV}, 6$ to $8 \mathrm{MeV}$, and 8 to $10 \mathrm{MeV}$. Since the source spectrum (see Fig. 2) decreases smoothly with increasing energy above $3 \mathrm{MeV}$, the effect of the coarse group structure, even after smoothing, is, for example, to underestimate the flux in the region 3 to $3.5 \mathrm{MeV}$, overestimate the flux in the region 3.5 to $4 \mathrm{MeV}$, underestimate the flux in the region 6 to $7 \mathrm{MeV}$, overestimate the flux in the region 7 to $8 \mathrm{MeV}$, etc. Looking first at Fig. 7 at the comparison on the centerline behind 6 in. of iron, the above noted undulations in the calculated spectra are particularly evident. The agreement is in general very good, however, and only in the regions centered around 1.5 and $2.5 \mathrm{MeV}$ does there appear to be any significant discrepancy. Since $295 \%$ of the calculated spectrum is uncollided, this discrepancy suggests that the average total cross section in these regions is too high (by about 5 percent) in the data set used.

In Figs. 8 and 9, comparisons are shown at 15 and 45 degrees of $f$ the centerline behind $4 \mathrm{in}$ : of iron. Here, the overall agreement is adequate at 15 degrees and inadequate at 45 degrees. The region above $1.5 \mathrm{MeV}$ is 


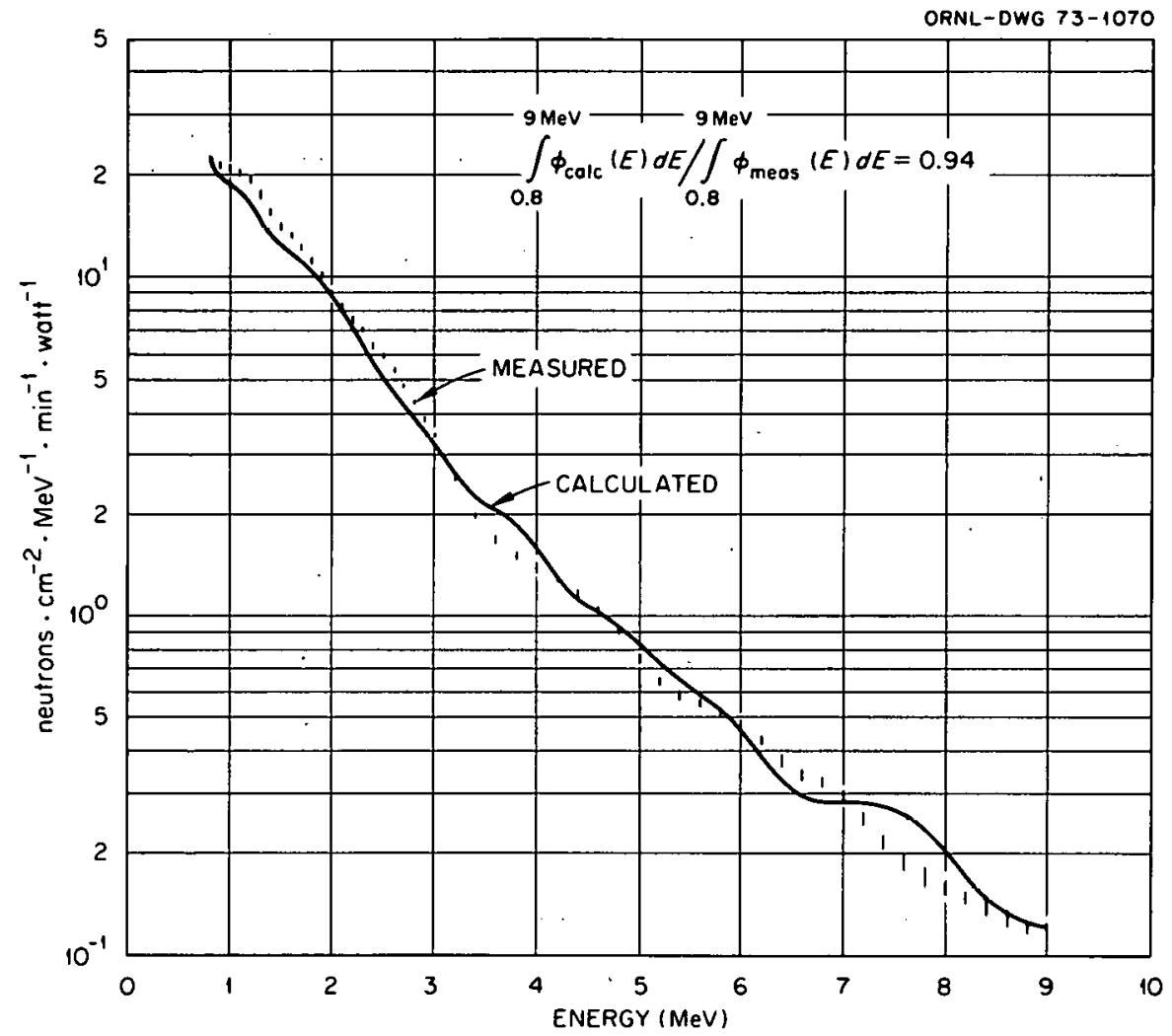

Fig. 7. Comparison of Calculated and Measured Neutron Spectra Above $0.8 \mathrm{MeV}$ on the Centerline Behind $6 \mathrm{in}$. of Iron. 


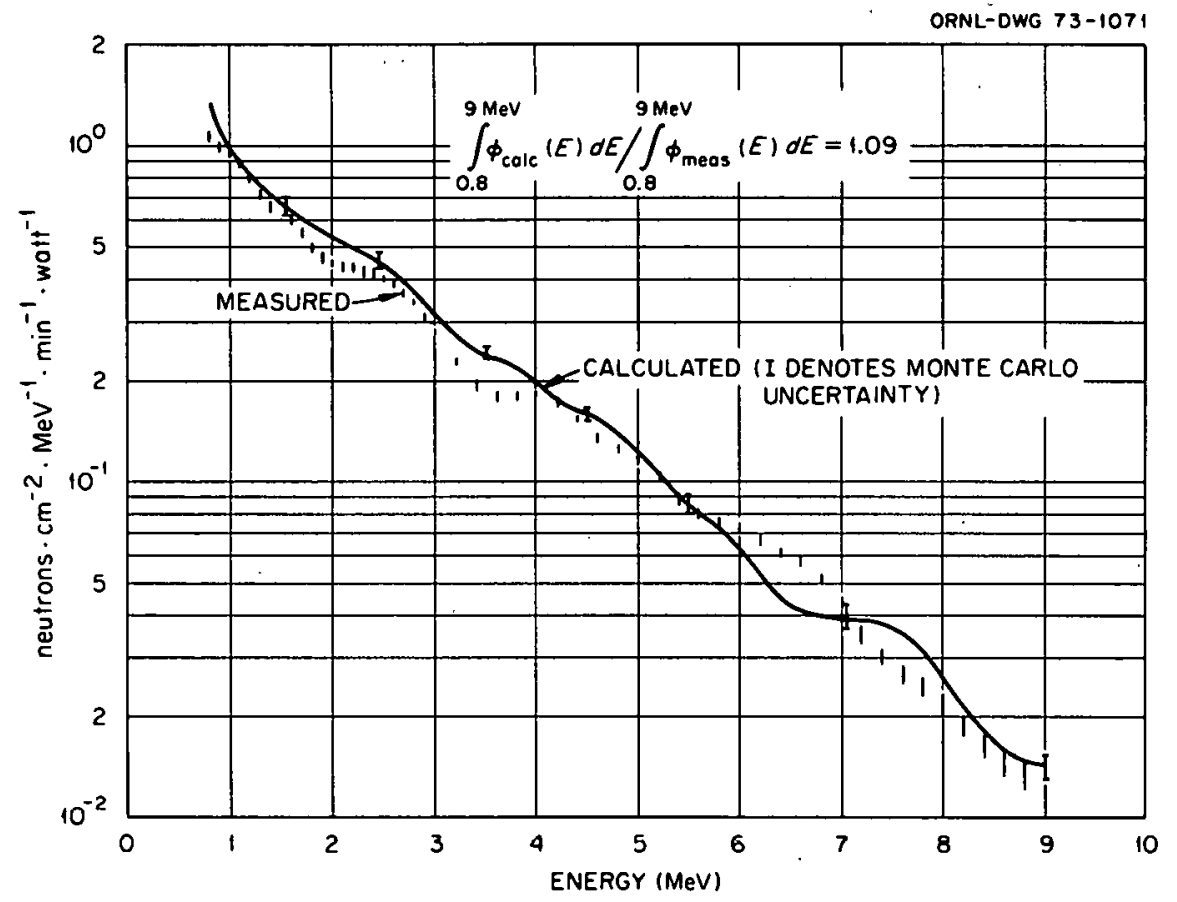

Fig. 8. Comparison of Calculated and Measured Spectra Above $0.8 \mathrm{MeV}$ at 15 Degrees Behind 4 in. of Iron. 


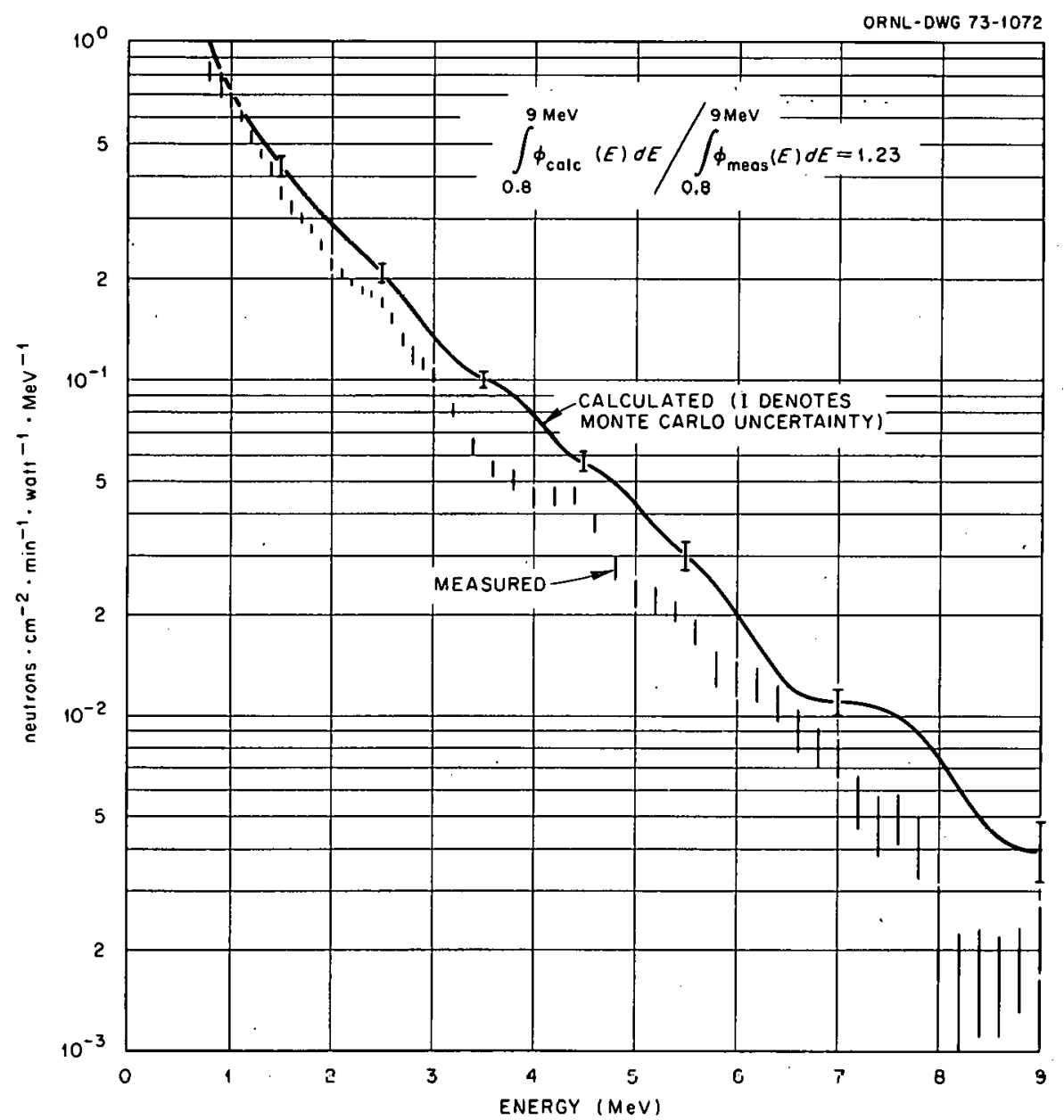

Fig. 9. Comparison of Calculated and Measured Spectra Above $0.8 \mathrm{MeV}$ at 45 Degrees Behind 4 in. of Iron. 
overpredicted in the calculations for the 45-degree case, indicating that errors exist in the angular distributions centered around 45 degrees used in the calculations. Part of this error may be due to the processing code which treats all inelastic scattering as isotropic, regardless of the angular distribution appearing in the data set. Since the angular distributions of inelastically scattered neutrons are often peaked forward, the processed angular distributions would indeed probably tend to overestimate 45-degree scattering, which might well explain some of the discrepancy. However, inaccuracies in the processed angular distributions from elastic scattering undoubtedly also contribute appreciably to the observed discrepancy, and may be due in part to the $P_{3}$ truncation of the data set performed by SUPERTOG. Thus, further calculations of the flux at 45 degrees using all the angular distribution data in MAT 4180-Mod. I in a "point" Monte Carlo code are necessary before definite conclusions can be drawn about the adequacy of the angular distribution data in the region above $0.8 \mathrm{MeV}$. All that can be said now is that use of a group processing code with $P_{3}$ and $P_{0}$ truncations of the angular distributions arising from elastic and inelastic scattering, respectively, plus point total cross sections is still inadequate to describe the experimental results at 45 degrees behind 4 in. of iron.

In Figs. 10-12 are shown the NE-213 comparisons behind 12 in. of iron. The comparison on the centerline shown in Fig. 10 indicates that the averaged total cross section in the region $\sim 1$ to $3.5 \mathrm{MeV}$ is too high, by approximately $8 \%$, since $i 88 \%$ of the calculated spectrum is due to unscattered neutrons. This measurement tests the total cross section much more sensitively than the centerline measurement behind 6 in., and hence 


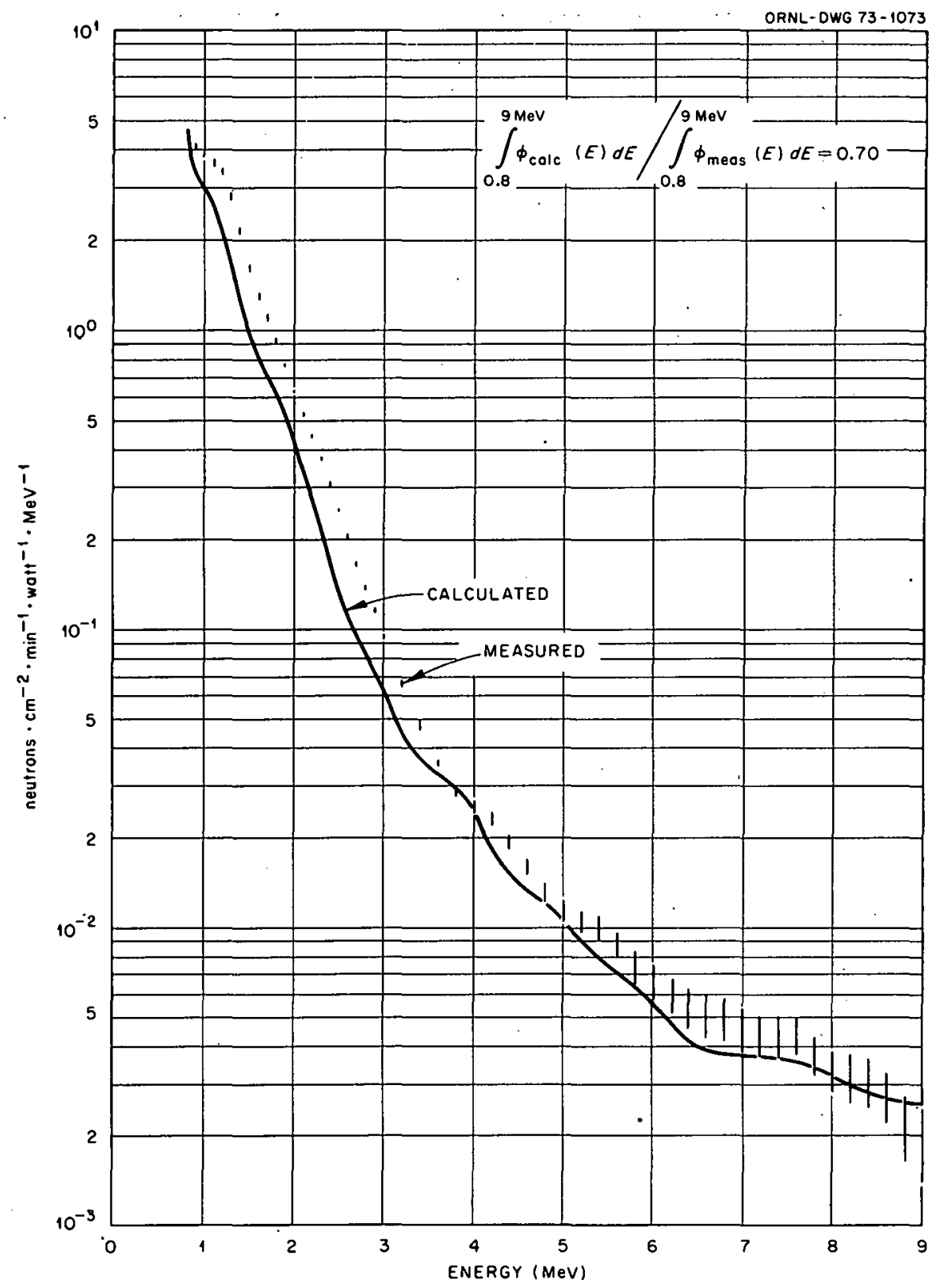

Fig. 10. Comparison of Calculated and Measured Spectra Above $0.8 \mathrm{MeV}$ on the Centerline Behind 12 in. of Iron. 


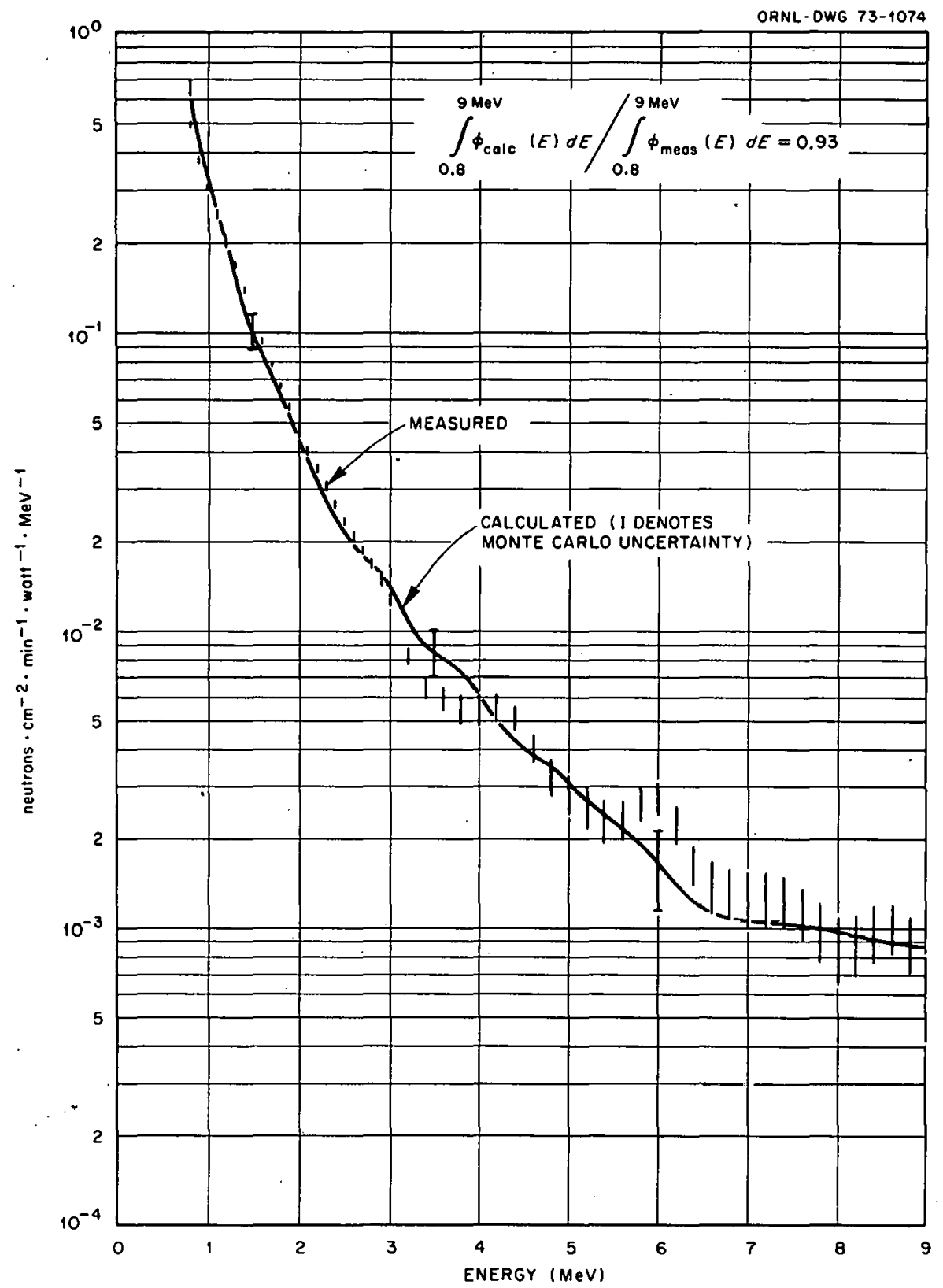

Fig. 11. Comparison of Calculated and Measured Spectra Above $0.8 \mathrm{MeV}$ at 15 Degrees Behind 12 in. of Iron. 


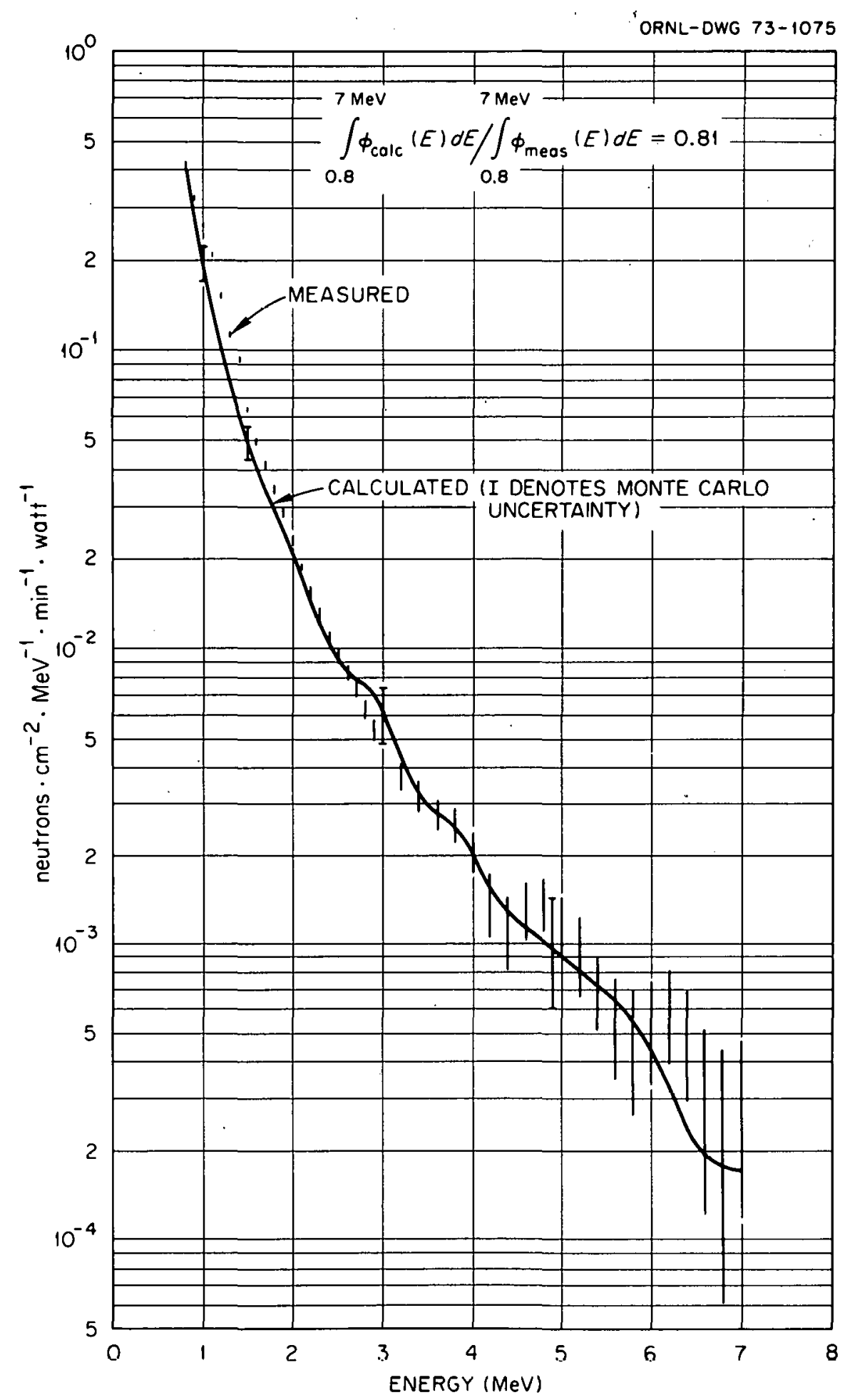

Fig. 12. Comparison of Calculated and Measured Spectra Above $0.8 \mathrm{MeV}$ at 45 Degrees Behind 12 in. of Iron. 
determines any errors in the total cross section far more accurately. This significant disagreement between the measured and calculated spectra is consistent with a similar disagreement between the measured and calculated uncollided flux behind 12 in. of iron that was found in an earlier experiment. 15 The point total cross-section data in the region 0.8 to $10 \mathrm{MeV}$ used in MAT 1101, MAT 1124, MAT 1180, MAT 4180, and MAT 4180-1 are identical and based on the measurements of Cerbone. ${ }^{16}$ These measurements were made with considerably better resolution than those performed earlier at Karlsruhe, 17 and showed deeper minima in the interference regions of the total cross section. It is conjectured that a measurement performed with better resolution than that used by Cerbone might indicate the presence of even deeper minima, and might well produce results more in agreement with the measurement in Fig. 10. The calculated spectra in Fig. 10 are very sensitive to these minima since the uncollided weighting factor for each point total cross section is proportional to $\exp \left(-2.60 \sigma_{t}\right)$, where $\sigma_{t}$ is in barns. Thus the average cross section in the range $E_{1}$ to $E_{2}$ is

$$
\bar{\sigma}_{t}=\int_{E_{1}}^{E_{2}} S(E) \sigma_{t}(E) \exp \left(-2.60 \sigma_{t}\right) d E \int_{E_{1}}^{E_{2}} S(E) \exp \left(-2.60 \sigma_{t}\right) d E,
$$

where $S(E)$ is the source spectrum derived from Fig. 2. It is the quantity $\bar{\sigma}_{t}$ that is about $8 \%$ too high in the region $\sim 1$ to $3.5 \mathrm{MeV}$.

The comparisons between calculation and measurement at 15 and $45 \mathrm{deg}-$ rees behind $12 \mathrm{in.}$ of iron are shown in Figs. 11 and 12 , respectively. There is reasonable agreement at 15 degrees but the calculations underpredict the spectrum in the region 0.9 to $1.7 \mathrm{MeV}$ at 45 degrees. The 
range of scattering angles that the neutrons undergo in reaching off centerline detectors is far greater in penetrating 12 in. of iron than 4 in. of iron, since many of the neutrons leaking the 12 in. slab are multiplyscattered. Hence the overprediction of scattering in the vicinity of 45 degrees observed behind $4 \mathrm{in}$. of iron and the underprediction observed behind $12 \mathrm{in.}$ of iron are not necessarily incompatible.

Figure 13 shows a comparison of the calculated and measured NE-213 spectra on the centerline behind $18 \mathrm{in.}$ of stainless, steel. The agreement is in general quite good, although there is probably significance in the slight differences centered around 0.85 and $2.75 \mathrm{MeV}$. Since at this centerline location only $28 \%$ of the neutrons are uncollided, the agreement indicates only that the effects of multiple scattering in the MeV region are treated correctly. Errors in the total cross section for stainless steel probably exist in the region above $\sim 0.5 \mathrm{MeV}$, however, because of the disagreement between the calculated and measured $10 \mathrm{in.} \mathrm{Bonner} \mathrm{ball} \mathrm{results}$ on the centerline behind $12 \mathrm{in.}$ of stainless steel, where $52 \%$ of the calculated counting rate is due to uncollided neutrons. If one assumes the 10-in. Bonner ball measurements made at 72 and 144 in. behind 18 in. of stainless steel are about $15 \%$ too high because of insufficient background subtraction, a very reasonable possibility, the results of all the 10-in. Bonner ball comparisons and the NE-213 comparison behind stainless steel indicate that, within the uncertainties of the measurement and the calculation, the derived cross-section set used for stainless steel contains only one significant deficiency in the region above $20.5 \mathrm{MeV}--$ the average total cross section is somewhat too high in the region $\sim 0.5$ to 2.6 MeV (see Table VII). 


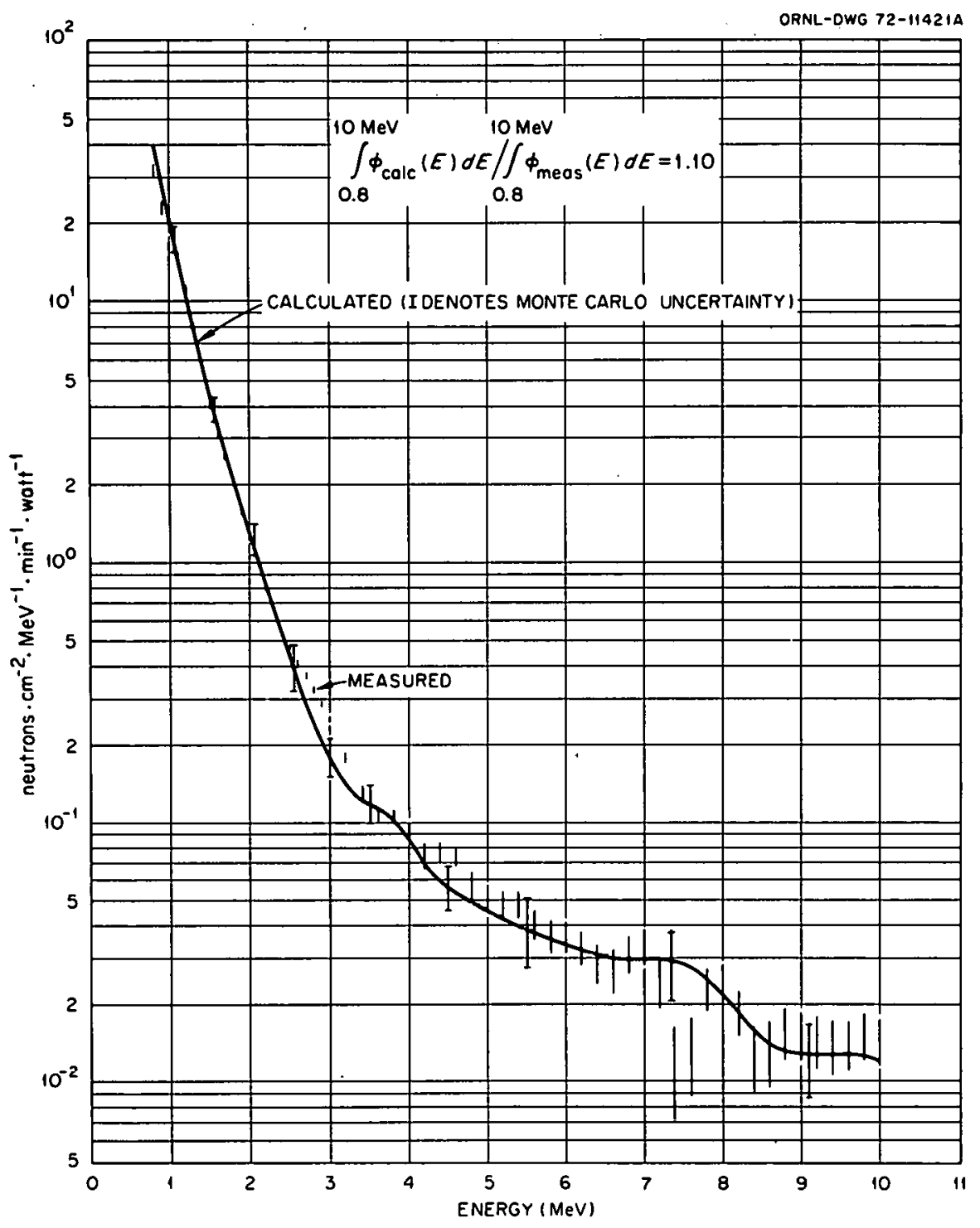

Fig. 13. Comparison of Calculated and Measured Spectra Above $0.8 \mathrm{MeV}$ on the Centerline Behind 18 in. of Stainless Steel. 
Figures 14 and 15 show the comparisons of the measured and calculated fluxes behind $12 \mathrm{in.}$ of iron in the Benjamin counter region $(60 \mathrm{keV}$ to 1.5 MeV). As with the NE-213 comparisons, all the calculations were smoothed with the resolution function of the spectrometer, which for the Benjamin counter was assumed to be $10 \%$ FWHM, independent of cnergy. Figure 14 shows the comparison on the centerline, where the calculations indicate $25 \%$ of the flux is uncollided. The agreement in shape and absolute magnitude. is very good with the exception of the region 60 to 90 $\mathrm{keV}$ and, to a lesser extent, the regions centered around $150 \mathrm{keV}$ and 220 $\mathrm{keV}$. The disagreement in the former region may well. be due to uncertainties in the measurement since this energy region represents the lower limit of reliability of the spectrometer system. The disagreement in the latter regions is probably due to errors in the cross-section set used in the calculation; in particular, the set overpredicts fluxes around $220 \mathrm{keV}$. Figure 15 shows the comparison off the centerline, and again the agreement is adequate with the exceptions and reservations already noted in Fig. 14 . There is now better agreement in the region 60 to $90 \mathrm{keV}$; but the peak in the vicinity of $80 \mathrm{keV}$ is still overpredicted. The calculations are now a little high in the region 400 to $600 \mathrm{keV}$, but not distressingly so. It is obvious from these two comparisons that the more important features of the cross-section structure for iron in the region $100 \mathrm{keV}$ to $1 \mathrm{MeV}$ are well represented by the MAT 4180-Mod. I data.

In Figs. 16 and 17 are shown similar comparisons behind 12 in. of stainless steel. In Fig. 16 a centerline comparison is shown for which the uncollided contribution is $6 \%$, and in Fig. 17 an off centerline comparison is shown. The disagreements occur basically in the same energy 


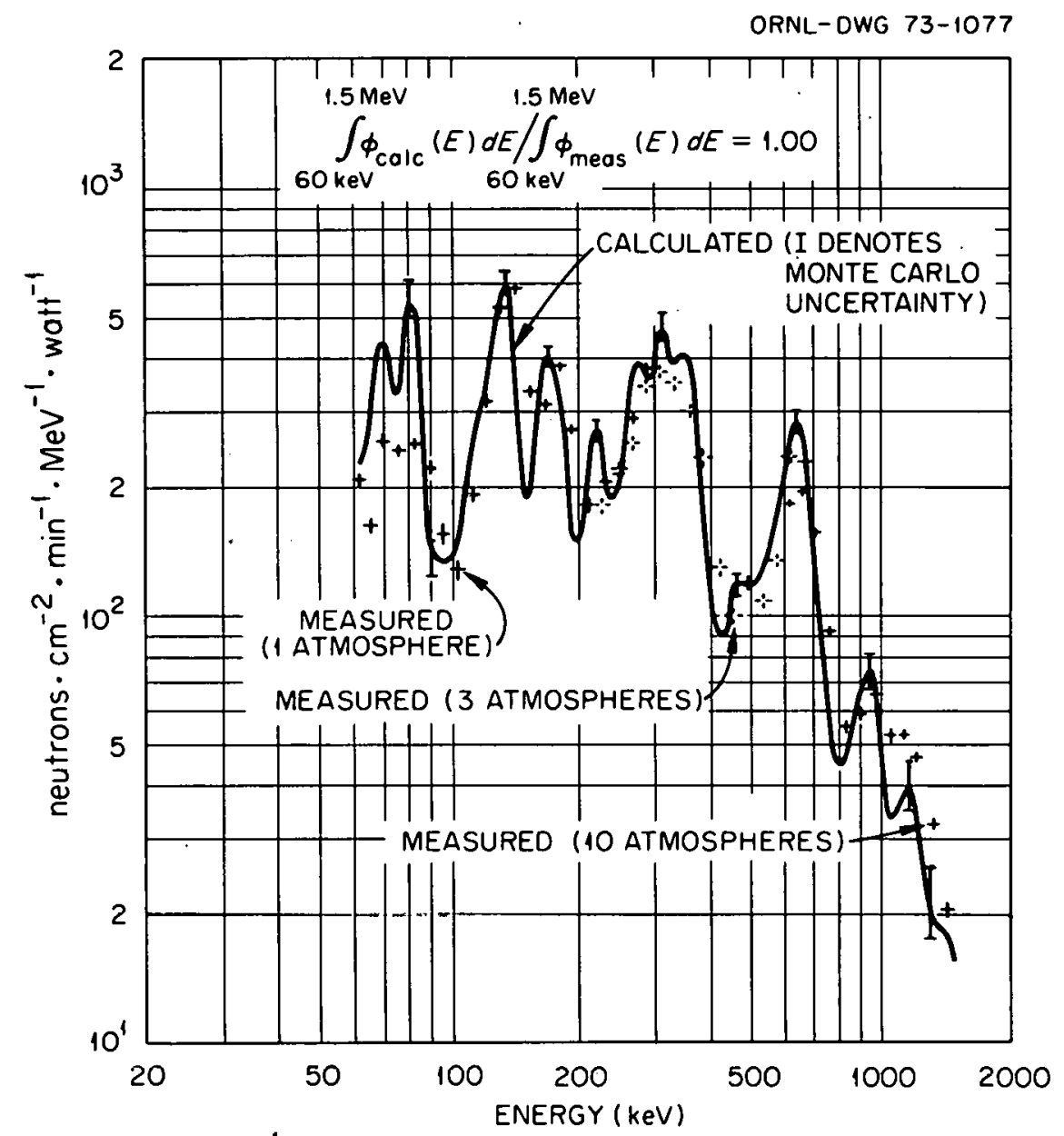

Fig. 14. Comparison of Calculated and Measured Spectra Between $60 \mathrm{keV}$ and $1.5 \mathrm{MeV}$ on the Centerline Behind 12 in. of Iron. 


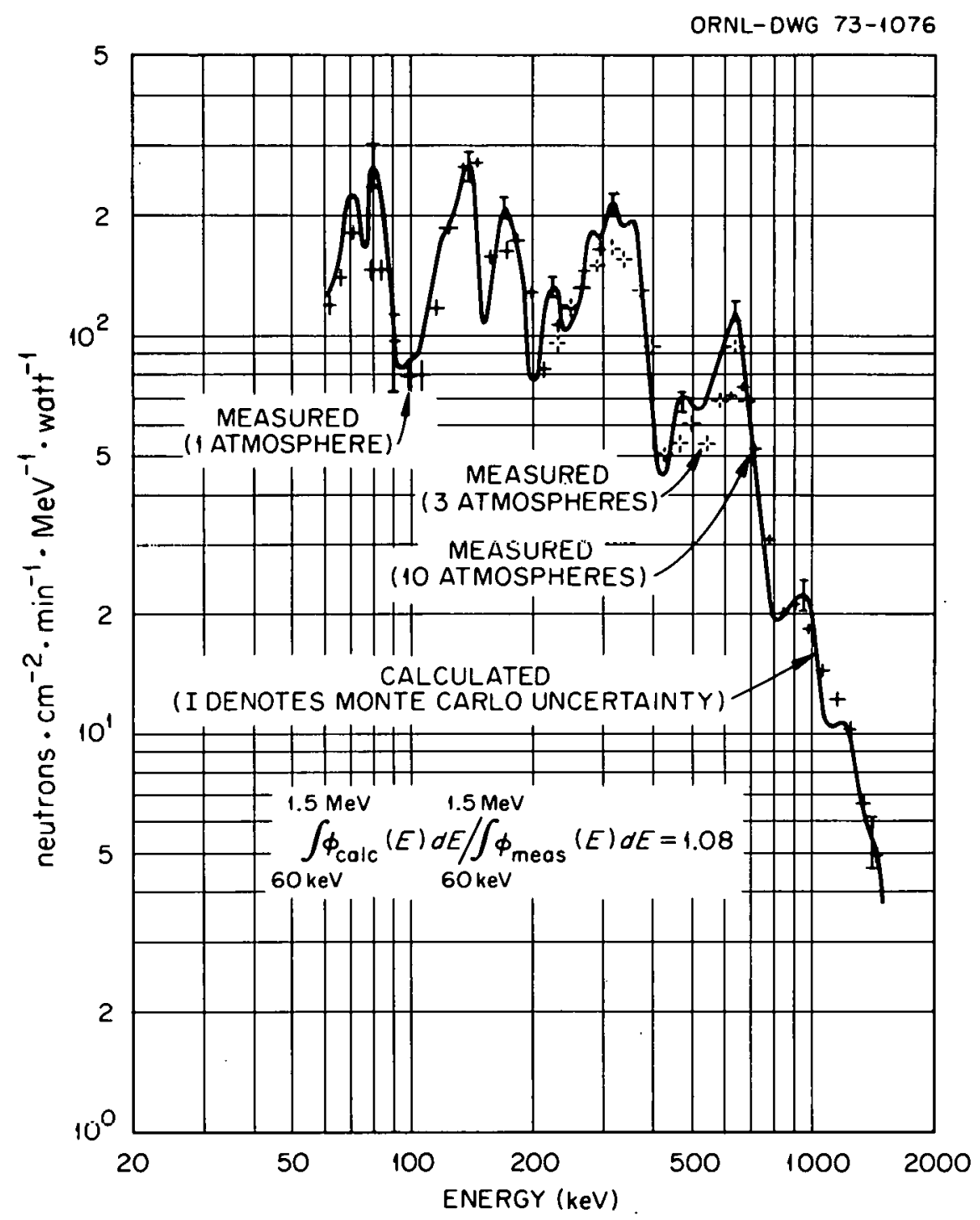

Fig. 15. Comparison of Calculated and Measured Spectra Between $60 \mathrm{keV}$ and $1.5 \mathrm{MeV}$ off the Centerline Behind $12 \mathrm{in.}$ of Iron. 


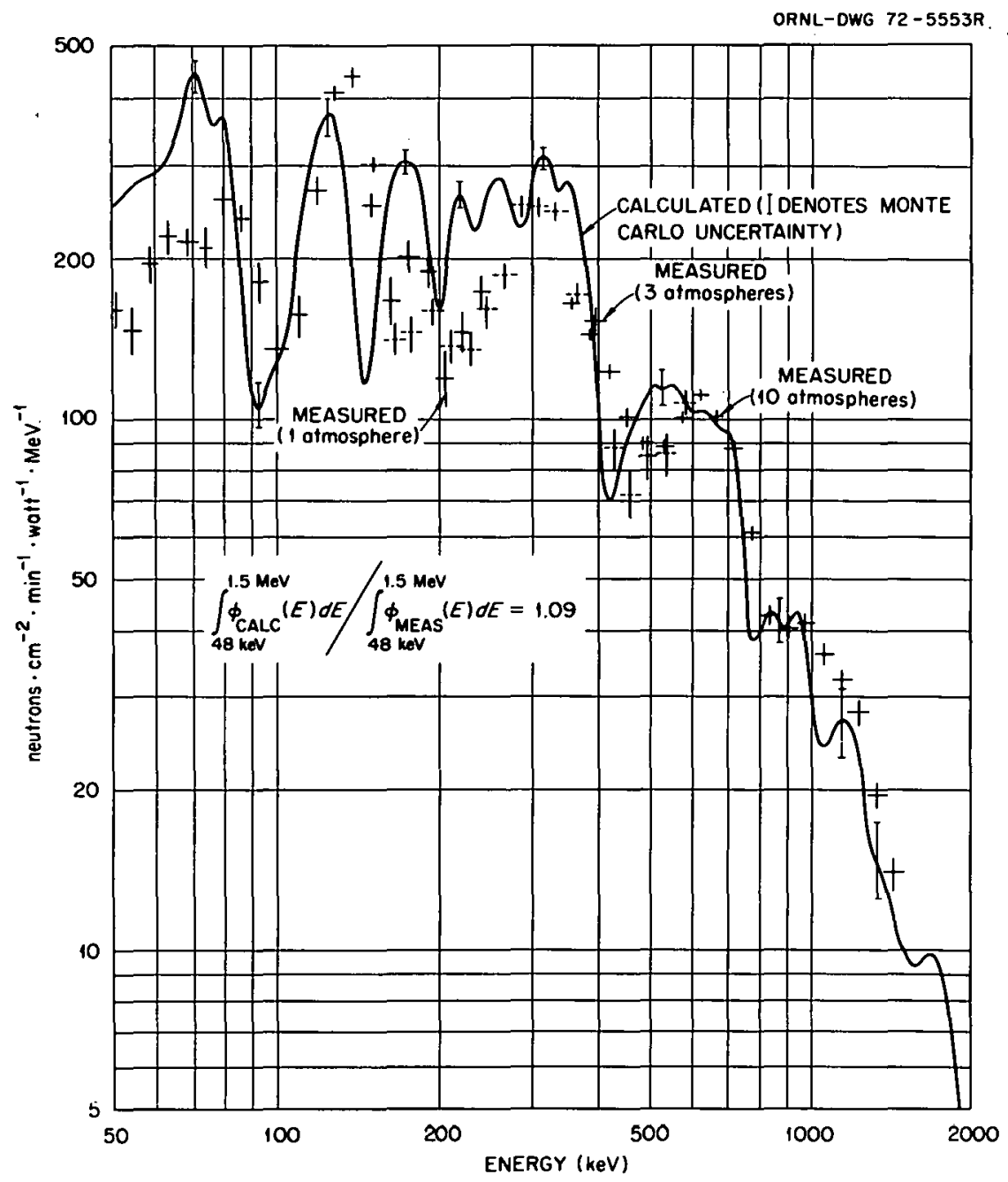

Fig. 16. Comparison of Calculated and Measured Spectra Between $48 \mathrm{keV}$ and $1.5 \mathrm{MeV}$ on the Centerline Behind $12 \mathrm{in.} \mathrm{of} \mathrm{Stainless} \mathrm{Steel.}$ 


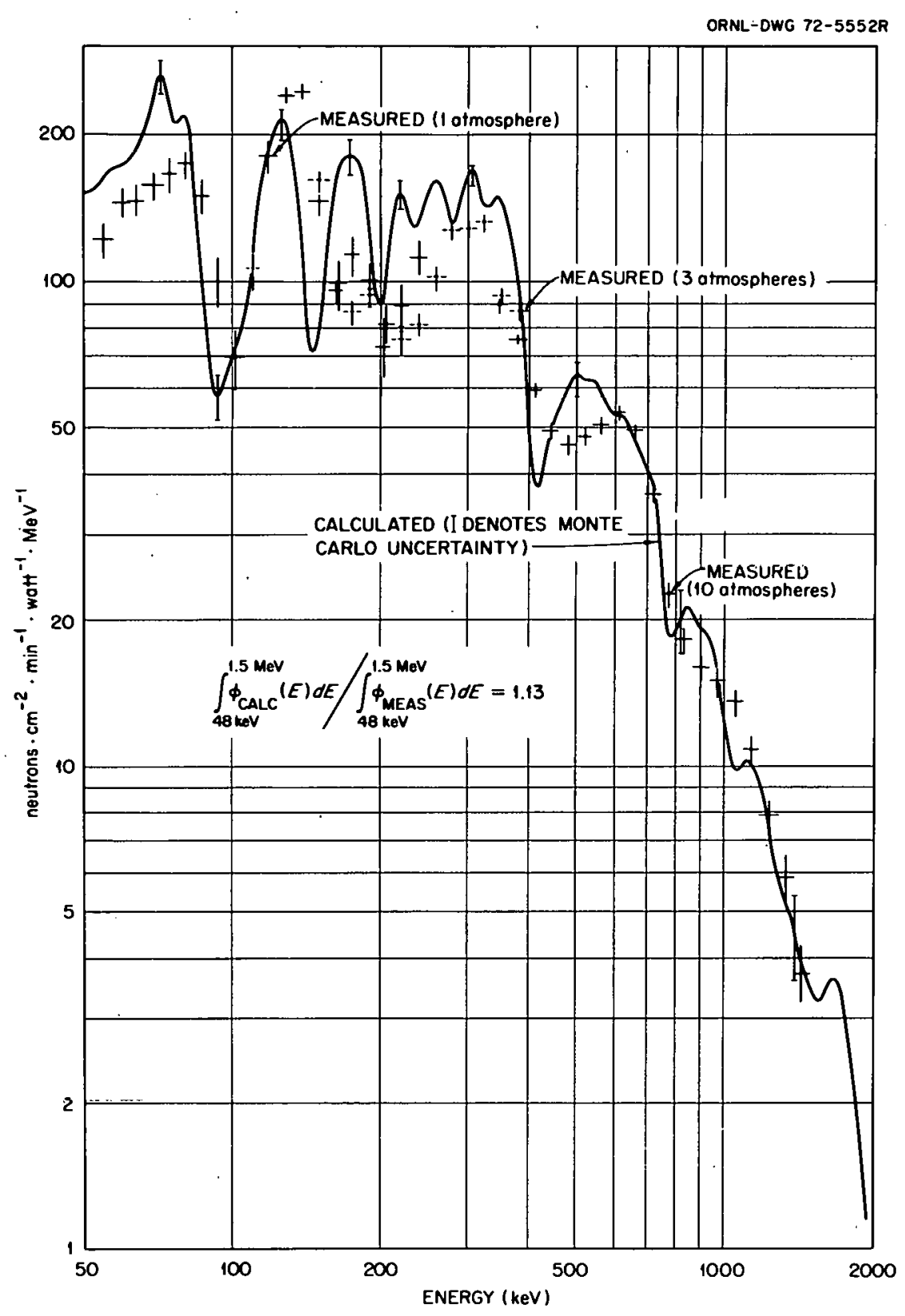

Fig. 17. Comparison of Calculated and Measured Spectra Between $48 \mathrm{keV}$ and $1.5 \mathrm{MeV}$ off the Centerline Behind 12 in. of Stainless Steel. 
regions behind the stainless steel as behind the iron, but in general the disagreements are somewhat magnified. Slight overpredictions are still made in the region around $500 \mathrm{keV}$. The disagreements centered sharply around 150 and $220 \mathrm{keV}$ behind the iron are now broader behind the stainless steel, extending from 125 to $150 \mathrm{keV}$ for the former region and from 160 to $270 \mathrm{keV}$ for the latter region. Since in one region the calculations are high and in the other low, there is little net effect in the flux integrated over both these regions, but errors in the cross-section set affecting neutrons in at. least the higher energy region are nonetheless apparent (correcting the errors affecting neutrons in the higher region alone may also produce agreement in the lower region because of differences in the transport to lower energies). In Fig. 18 the centerline comparison is shown behind $18 \mathrm{in}$. of stainless steel, where the uncollided contribution is completely negligible $(0.4 \%)$. The general features of the calculation relative to the measurement behind $12 \mathrm{in.}$ are maintained behind $18 \mathrm{in.}$, i.e., a slight overprediction in the region around $500 \mathrm{keV}$ and from 160 to $230 \mathrm{keV}$, and an underprediction in the region from 130 to $150 \mathrm{keV}$. The agreement in the region 40 to $80 \mathrm{keV}$ is now much better, but there still exists an underprediction around $90 \mathrm{keV}$. In general, the calculations do not agree with the measurements behind the stainless steel quite as well as behind the iron in the energy region $100 \mathrm{keV}$ to $1 \mathrm{MeV}$, leading to the conclusion that significant cross-section errors exist in the chromium and/or nickel ENDF/B-III sets in addition to less significant errors in the 4180-Mod. I set for iron that affect neutrons in this energy region. 


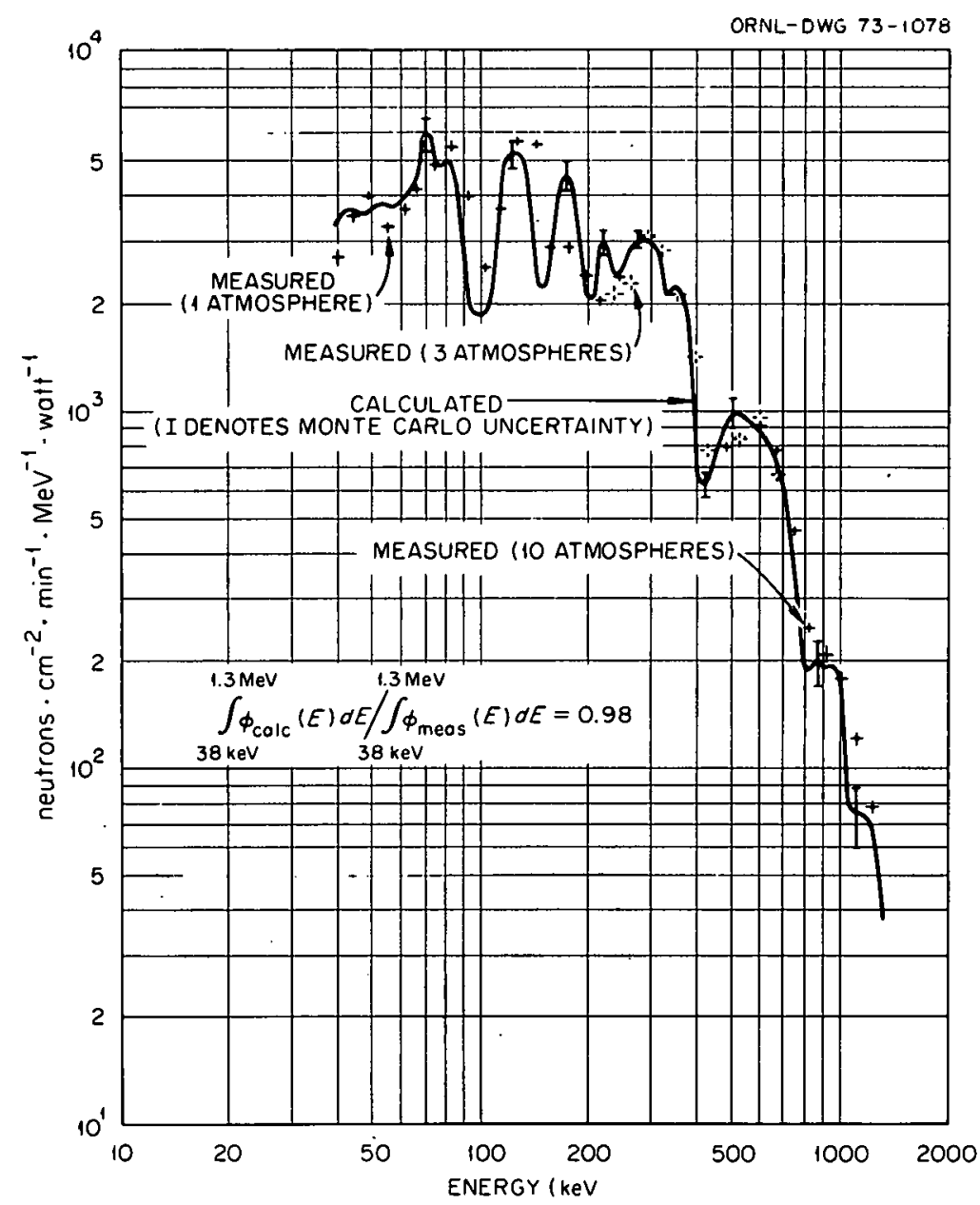

Fig. 18. Comparison of Calculated and Measured Spectra Between $38 \mathrm{keV}$ and $1.3 \mathrm{MeV}$ on the Centerline Behind $18 \mathrm{in.}$ of Stainless Steel. 


\section{CONCLUSIONS}

The most significant disagreement between the calculations and the present measurements behind iron leads to the conclusion that the average total cross section in the region $\sim 1$ to $3.5 \mathrm{MeV}$ is too high by about 100 to 200 millibarns in the 4180-Mod. 1 and ENDF/B-III (MAT 1180) evaluations. This conclusion is in agreement with the results of an earlier experiment performed at the TSF. ${ }^{15}$ The remaining significant disagreement suggests that the angular distribution of scattering in the region above $\sim 2 \mathrm{MeV}$ is inadequate at least for angles of scattering in the vicinity of 45 degrees. The possibility exists, however, that this disagreement is due to truncated $\mathrm{P}_{0}$ and $\mathrm{P}_{3}$ distributions used in the processing code and the disagreement does not necessarily confirm the presence of errors in the 4180-Mod. I evaluation. Less significant disagreements also suggest minor cross-section errors leading to neutrons in the vicinity of $150 \mathrm{keV}$ and $220 \mathrm{keV}$.

From the comparisons of calculated and measured results behind stainless steel, the above conclusions regarding iron are reinforced. Additional significant errors in the chromium and/or nickel cross sections affccting neutrons in the regions 130 to $250 \mathrm{keV}$ and above $\sim 500 \mathrm{keV}$ also are indicated.

In general, however, there is remarkably good agreement between the calculations and measurements, and the overall conclusion to be drawn is that the 4180-Mod. I data set for iron using the Harvey total cross sections for iron from 80 to $500 \mathrm{keV}$, gives good agreement with most of the measurements presented. The use of previous iron evaluations give signifi- 
cant errors in the transmission of neutrons through thick iron shields. While these good comparisons show that accurate calculations can be performed for up to 36 in. of iron for the configurations used in the experiment, sensitivity studies should be performed to relate the comparisons to design problems where the source spectrum and "detector" response functions may be quite different.

\section{ACKNOWLEDGMENTS}

The authors wish to acknowledge the efforts of all the personnel at the Tower Shielding Facility for performing the excellent measurements described here, including K. M. Henry, Jr., L. B. Holland, J. L. Hull, J. J. Manning, J. N. Money, and R. M. Freestone, Jr. We also acknowledge the support of C. E. Clifford and F. R. Mynatt of this laboratory in providing invaluable advice on both the experimental and calculational phases of this work. 


\section{REFERENCES}

1. B. K. Malaviya, N. N. Kaushal, M. Becker, E. T. Burns, A. Ginsberg, and E. R. Gaerttner, "Experimental and Analytical Studies of Fast Neutron Transport in Iron," Nucl. Sci. Eng. 47, 329 (1972).

2. W. R. Burrus, "Utilization of A Priori Information in the Statistical Interpretation of Measured Distributions," Dissertation, The Ohio State University, ORNL-3743, Oak Ridge National Laboratory (1964).

3. W. R. Burrus and V. V. Verbinski, Proceedings of the Special Session on Fast Neutron Spectroscopy, 1964 Winter Meeting of the American Nuclear Society, San Francisco, California, Shielding Division Report ANS-SD-2, p. 148.

4. P. W. Benjamin, C. D. Kemshall, and A. Brickstock, "The Analysis of Recoil Proton Spectra," AWRE-09/68, Atomic Weapons Research Establishment (1968).

5. T. V. Blosser and R. M. Freestone, Jr., "Development of an EpithermalNeutron Spectrometer," Neutron Phys. Div. Ann. Prog. Rept. Aug. $1_{2}$ 1965, ORNL-3858, Vol. I, Oak Ridge National Laboratory (1965).

6. R. E. Maerker, L: R. Williams, F. R. Mynatt, and N. M. Greene, "Response Functions for Bonner Ball Neutron Detectors," ORNL-TM-3451, Oak Ridge National Laboratory (1971).

7. R. E. Maerker, F. J. Muckenthaler, J. J. Manning, J. L. Hull, J. N. Money, K. M. Henry, Jr., and R. M. Freestone, Jr., "Calibration of the Bonner Ball Neutron Detectors Used at the Tower Shielding Facility," ORNL-TM-3465, Oak Ridge National Laboratory (1971).

8. A more complete description of this collimator appears in R. E. Maerker and F. J. Muckenthaler, "The Absolute Neutron Spectrum Emerging Through a 15-1/4-in. Collimator from the TSR-II Reactor at the Tower Shielding Facility," ORNL-TM-4010, Oak Ridge National Laboratory (1972).

9. E. A. Straker, P. N. Stevens, D. C. Irving, and V. R. Cain, "The MORSE Code - A Multigroup Neutron and Gamma-Ray Monte Carlo Transport Code," ORNL-4585, Oak Ridge National Laboratory (1970). 
10. This set was evaluated by F. G. Perey of Oak Ridge National Laboratory.

11. J. A. Harvey, "KeV Neutron Total Cross Section Measurements at ORELA," paper presented at the National Topical Meeting on New Developments in Reactor Physics and Shielding, Sept. 12-15, 1972, Kiamesha Lake, N.Y., CONF-720901, Book 2, p. 1075 (1972).

12. R. Q. Wright, J. L. Lucius, N. M. Greene, and C. W. Craven, Jr., "SUPERTOG: A Program to Generate Fine Group Constants and $P_{n}$ Scattering Matrices from ENDF/B," ORNL-TM-2679, Oak Ridge National. Laboratory (1966).

13. It was, however, the underprediction of most of the Bonner ball counting rates in this experiment by a factor of about 1.5 of the calculations using the MAT 1124 set, where the $24-\mathrm{keV}$ window is too low, that led to the recent re-measurements of the minima in the total cross section for iron in the region 80 to $500 \mathrm{keV}$ which have been incorporated into the 4180-Mod. I set. These minima are generally lower and/or broader than those appearing in the MAT 1124 or MAT 1180 sets.

14. E. A. Straker, "Experimental Evaluation of Minima in the Total Neutron Cross Sections of Several Shielding Materials," ORNL-TM-2242, Oak Ridge National Laboratory (1968).

15. R. E. Maerker, "SDTl. Iron Broomstick Experiment - An Experimental Check of Neutron Total Cross Sections," ORNL-TM-3867 and ENDF-166 (Revised), Oak Ridge National Laboratory (1972). For both the present experiment and the SDTl experiment, the effect of possible fine structure in the source beam was investigated and found to be negligible.

16. A. D. Carlson, R. J. Cerbone, and D. F. Willoughby, "Measurement of Neutron Penetration Standards, Volume II, High Resolution Measurements of the Total Neutron Cross Sections of Nitrogen and Iron," GA-9.149 and DASA Report No. 2289, Gulf General Atomic (1969). 
17. S. Cierjacks et al., "High Resolution Total Neutron Cross Sections Between 0.5 - $50 \mathrm{MeV}, " \mathrm{KFK} 1000$, EUR 3963e. EANDC(E)-Ill(U), Gesellschaft Fur Kernsforschung M.B.H. Karlsruhe (1968). 
INTERNAL DISTRIBUTION

$\begin{aligned} \text { 1-3. } & \text { L. S. Abbott } \\ \text { 4. } & \text { J. L. Anderson } \\ \text { 5. } & \text { G. T. Chapman } \\ \text { 6-11. } & \text { C. E. Clifford } \\ \text { 12. } & \text { G. F. Flanagan } \\ \text { 13. } & \text { W. O. Harms } \\ \text { 14. } & \text { K. M. Henry } \\ \text { 15. } & \text { L. B. Holland } \\ \text { 16. } & \text { J. Lewin } \\ \text { 7-23. } & \text { R. E. Maerker } \\ \text { 24. } & \text { F. C. Maienschein } \\ 25 . & \text { B. J. McGregor } \\ 26 . & \text { F. J. Muckenthaler } \\ 27 . & \text { F. R. Mynatt } \\ 28 . & \text { E. M. Oblow } \\ 29 . & \text { F. G. Perey } \\ 30 . & \text { W. A. Rhoades }\end{aligned}$
31. R. T. Santoro
32. H. E. Seagren
33. P.N. Stevens
34. D. B. Trauger
35. D. K. Trubey
36. G. E. Whitesides
37. A. Zucker
38. H. Feshbach (consultant)
39. P. F. Fox (consultant)
40. C.R. Mehl (consultant)
41. H. T. Motz (consultant)
42-43. Central Research Library
44. ORNL Y-12 Technical Library Document Reference Section
45-47. Laboratory Records Department 48. Laboratory Records ORNL RC 49. ORNL Putent Office

\section{EXTERNAL DISTRIBUTION}

50-51. USAEC Division of Reactor Development and Technology, Washington, D. C. 20545: Director

52. USAEC-RDT Senior Site Representative, Oak Ridge National Laboratory, P. O. Box X, Oak Ridge, TN. 37830

53. USAEC Oak Ridge Operations Office, P. O. Box E, Oak Ridge, TN 37830: Research and Technical Support Division

54-250. For distribution as shown in TID-4500 Distribution Category, UC-79d, Liquid Metal Fast Breeder Reactors Physics 